\title{
Self-assembly of Alkyl Chains of Fatty Acids in Papermaking Systems: A Review of Related Pitch Issues, Hydrophobic Sizing, and pH Effects
}

\author{
Martin A. Hubbe, ${ }^{\mathrm{a}, *}$ Douglas S. McLean, ${ }^{\mathrm{b}}$ Karen R. Stack,,${ }^{\mathrm{c}}$ Xiaomin Lu, ${ }^{\mathrm{a}}$ Anders Strand, \\ and Anna Sundberg e
}

\begin{abstract}
This review article considers the role of fatty acids and the mutual association of their long-chain (e.g. C18) alkyl and alkenyl groups in some important aspects of papermaking. In particular, published findings suggest that interactions involving fatty acids present as condensed monolayer films can play a controlling role in pitch deposition problems. Self-association among the tails of fatty acids and their soaps also helps to explain some puzzling aspects of hydrophobic sizing of paper. When fatty acids and their soaps are present as monolayers in papermaking systems, the $\mathrm{pH}$ values associated with their dissociation, i.e. their $\mathrm{p} K_{\mathrm{a}}$ values, tend to be strongly shifted. Mutual association also appears to favor non-equilibrium multilayer structures that are tacky and insoluble, possibly serving as a nucleus for deposition of wood extractives, such, as resins and triglyceride fats, in pulp and paper systems.
\end{abstract}

Keywords: Wood extractives; Hydrophobic effect; Papermaking; Pitch deposits; Sizing of paper

Contact information: a: North Carolina State University, Dept. of Forest Biomaterials, Campus Box 8005, Raleigh, NC 27695-8005; b: Nalco Water - An Ecolab Company, Tasmania; c: University of Tasmania, School of Natural Sciences, Box 75 Hobart, Tasmania, 7000, Australia; d: Mirka Oy, Pensalavägen 210, 66850 Jeppo, Finland; e: Åbo Akademi University, Laboratory of Natural Materials Technology,

Porthansgatan 3, 20500 Turku, Finland; *Corresponding author: hubbe@ncsu.edu

\section{Contents}

Introduction . . . . . . . . . . . . 4592

Theoretical concepts . . . . . . . . . . . . 4593

Dissociation and $\mathrm{pK}$. . . . ..... 4593

Multi-carboxylic monomeric acids 4595

Polymeric carboxylic acids . . . . . 4596

Monomeric fatty acids and soaps 4597

Micellization . . . . . . . . . . . . . . 4598

Self-assembly at interfaces . . . . . 4599

Free energy of association . . . . . 4600

Colloidal $\mathrm{p} K_{\mathrm{a}} \ldots . . . \ldots . . . . . . .44601$

Multivalent counter-ion effects . . . 4602

Association of carboxyl groups ... 4604

Pitch problems and control . . . . . . . 4605

Pitch problems in paper mills . . . . 4605

pH shock . . . . . . . . . . . . 4607

Water hardness shock . . . . . . . 4607

Combined pH \& hardness . . . . . 4608

Mechanical effects . . . . . . . . 4609

Proactive pitch management . . . . 4610
Seasoning . . . . . . . . . . 4610

Deresination 4611

Additives to control pitch . . . . 4612

Aluminum sulfate .......... 4613

High-charge cationic polymers 4613

Enzymatic treatments . . . . . . . 4614

Sizing strategies involving fatty acids $\quad 4615$ Inexpensive and eco-friendly . . . . 4615 How to anchor soap compounds . . 4617 Instability \& overturn of monolayers 4618 Implications for reactive sizing . . . 4619

Broader implications . . . . . . . . . . . 4621

Solid wettability . . . . . . . . . . . . 4621

Hydrophobic chitosan sponges . . . 4621

Flotation de-inking . . . . . . . . . . . 4621

Protection of metal vs. corrosion 4621

Superhydrophobic systems . . . . . . 4622

Test methods for $\mathrm{p} K_{\mathrm{a}}$ values . . . . . 4622

Concluding remarks . . . . . . . . . . 4622 


\section{INTRODUCTION}

\section{Importance of the Topic}

The extractives component of wood material, which includes various fatty acids and their esters, has long presented a series of challenges to the pulp and paper industry, including outbreaks of pitch deposition and effects related to the hydrophilic or hydrophobic character of the resulting paper. Though the wood extractives comprise only about 1 to $5 \%$ of the dry mass of hardwood and 3 to $8 \%$ of that of softwood (Biermann 1996), they are usually a nuisance, but sometimes also of value, as in the case of rosin products and turpentine. Previous reviews of these extractives and their effects mainly have emphasized effects due to components and topics other than the fatty acids; for instance, the resin acids often comprise a more major fraction of material found in pitch-like deposits in paper machine systems (Allen 2000b; Back 2000). Also, the resin acids are well known to impart water-resistance to paper, i.e. to confer "rosin sizing" (Vandenberg and Spurlin 1967). This review article considers a hypothesis that the fatty acids and their esters - and specifically the tendency of mutual association of the alkyl chains of the fatty acids - often play a highly influential role in the behavior of extractive materials present within papermaking systems. A better understanding of these relationships has the potential to contribute to progress in the following areas:

- Prediction of conditions leading to deposition of wood-derived hydrophobic compounds in paper machine systems

- Development of new and improved pitch-control measures and related chemical additives and processes

- Developments in paper sizing technology that make use of fatty acids, a group of highly available, inexpensive, and relatively environmentally friendly compounds

- Progress in understanding some puzzling aspects related to the behavior of paper machine systems in which fatty acids, their soaps, and their esters are present in significant amounts

This article is organized around the following central observation: It has been found that fatty acid compounds, including oleic, stearic, and palmitic acids, etc., dissociate at a much higher $\mathrm{pH}$ compared to analogous compounds that do not have long alkyl $\left(\mathrm{CH}_{3}-\mathrm{CH}_{2}-\right.$ $\mathrm{CH}_{2}-\mathrm{CH}_{2}-$ etc.) tails (Nyrén and Back 1958a,b; McLean et al. 2005a; Strand 2013; Pashkovskaya et al. 2018). The fatty acids naturally present in wood materials tend to be dominated by 16-carbon or 18-carbon chain length and either one, two, or three $\mathrm{C}=\mathrm{C}$ double bonds (Vercoe et al. 2004). The dissociation of such fatty acids is often suppressed until the $\mathrm{pH}$ is raised two or three units higher than such compounds as acetic acid, especially at a relatively low ionic strength of solution (McLean et al. 2005a). This review article will consider various reported evidence suggesting that the mechanisms underlying this effect, called the "colloidal $\mathrm{p} K_{\mathrm{a}}$ ", may help in the understanding of a variety of other hard-to-explain phenomena in papermaking systems.

\section{Hypotheses}

The following hypotheses will be considered in this article as a means of focusing attention on the role of mutual association of relatively long alkyl chains (say with more than $14 \mathrm{CH}_{2}$ groups) in pulp and paper operations and some other systems: 
1. It is proposed that certain distinctive behavior of wood extractives in papermaking systems, as a function of $\mathrm{pH}$, can be better explained when taking into account a tendency of mutual association of long-chain alkyl (or alkenyl) groups.

2. It is proposed that certain effects of $\mathrm{pH}$ on the tendency of wood extractives to form deposits can be explained by the colloidal $\mathrm{p} K_{\mathrm{a}}$ concept.

3. It is proposed that the relative lack of progress, up to this point, in development of hydrophobic sizing systems for paper based on fatty acids and their soaps can be explained by the colloidal $\mathrm{p} K_{\mathrm{a}}$ concept and the close packing of the alkyl (or alkenyl) chains.

4. It is proposed that the mutual association of alkyl (or alkenyl) chains also can help to explain the effectiveness of certain alkaline or "reactive" sizing systems, such as those involving the use of alkylketene dimer (AKD) and alkenylsuccinic anhydride (ASA)

To address these hypotheses, in the light of published articles, the first step will be to review some theoretical concepts. Also, various evidence to support such concepts will be reviewed. The concepts include theories of the dissociation of carboxylic acids, factors that affect the $\mathrm{pH}$ at which half of those groups are dissociated (i.e. the $\mathrm{p} K_{\mathrm{a}}$ ), the formation of monomolecular layers of fatty acids and their soaps at interfaces, a concept called "colloidal $\mathrm{p} K_{\mathrm{a}}$," and a variety of competing effects that can be expected to obscure or add to effects that can be attributed to fatty acids. The next point of focus will be possible ways in which the tendency of mutual association of fatty acid alkyl chains can affect pitchcontrol strategies, hydrophobic sizing of paper, and some broader applications, such as adhesion to surfaces, soil wettability, and superhydrophobicity in systems where fatty acids and their soaps are present.

This document builds upon progress achieved by others. Such progress has been summarized in review articles and monographs, which deal in a broad way with pitch deposition and hydrophobic sizing effects in pulp and paper mill systems (Allen 1980, 2000a,b; Back 2000; Hubbe et al. 2006; McLean 2008; Tanase-Opedal et al. 2011a). Analytical procedures to quantify wood resins in papermaking processes were reviewed by Valto et al. (2012).

\section{THEORETICAL CONCEPTS}

\section{Dissociation of Weak Acids and the $\mathrm{pKa}$ Value}

Because the main points to be considered in this review article involve the $\mathrm{pH}$ of dissociation of different carboxylic acid groups, some basics will be summarized here. When a pure carboxylic acid is placed in water, the $\mathrm{pH}$ value will determine the state of ionization. The equilibrium expression, for each class of carboxylic acid group, can be described by Eq. 1.

$$
\mathrm{RCOOH}+\mathrm{H}_{2} \mathrm{O} \rightleftharpoons \mathrm{RCOO}^{-}+\mathrm{H}_{3} \mathrm{O}^{+}
$$

When the net concentration and other parameters such as temperature are known, the extent of dissociation ordinarily can be obtained by use of published values of acid dissociation constants, which are generally defined for each type of carboxylic acid according to Eq. 2: 


$$
K_{\mathrm{a}}=\left[\mathrm{RCOO}^{-}\right] *\left[\mathrm{H}_{3} \mathrm{O}^{+}\right] /[\mathrm{RCOOH}]
$$

Analogous to the definition of $\mathrm{pH}$, the $\mathrm{p} K_{\mathrm{a}}$ is defined as the negative logarithm (base 10) of the $K_{\mathrm{a}}$ value, as in Eq. 3:

$$
\mathrm{p} K_{\mathrm{a}}=-\log K_{\mathrm{a}}
$$

To illustrate the practical effects of these relationships, Fig. 1 shows how the dissociation of a simple carboxylic acid, acetic acid, changes its form in aqueous solution depending on the $\mathrm{pH}$. As shown in the figure, the dissociation does not take place all at once. Rather, about $90 \%$ of the transition from the uncharged to the fully charged state, within a population of such groups, will happen within a span of two units of $\mathrm{pH}$. The $\mathrm{p} K_{\mathrm{a}}$ value is in the center of this range, where $50 \%$ of the groups are ionized. The plotted line is based on Eq. 4:

$$
\text { Fraction ionized }=1 /\left[1+\left(10^{-\mathrm{pH}} / 10^{-\mathrm{p} K \mathrm{a}}\right)\right]
$$

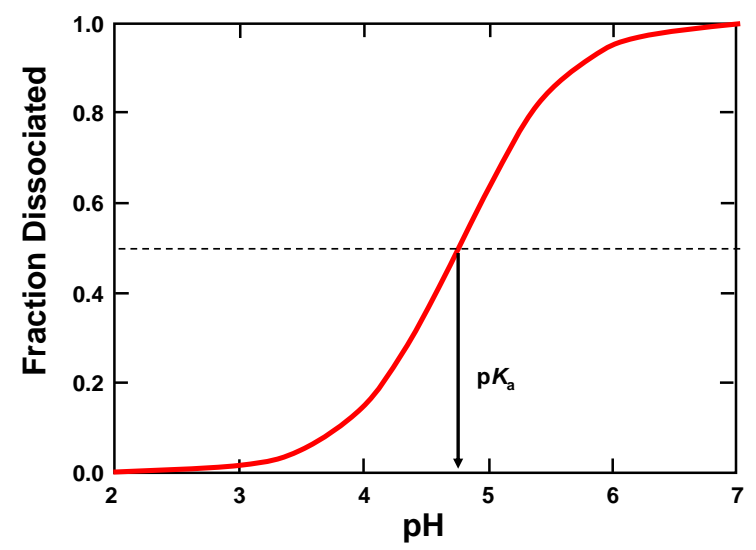

Fig. 1. Dissociation of aqueous acetic acid as a function of $\mathrm{pH}$. Curve calculated based on a $\mathrm{p} K_{\mathrm{a}}$ value of 4.757 , as reported by Mesmer (1989)

Evaluation of the $\mathrm{p} K_{\mathrm{a}}$ values of fatty acids having chain lengths above about 14 can be challenging, partly due to their relatively low solubility in water, especially in their uncharged state. One of the earliest strategies to get around this problem has been to employ a water-alcohol mixture as a solvent. By using a mixture of water and ethanol, White (1950) estimated the $\mathrm{p} K_{\mathrm{a}}$ values of palmitic and oleic acids, respectively, to be 5.06 and 5.02. Earlier work, using related methods, obtained $\mathrm{p} K_{\mathrm{a}}$ values in the range 4.9 to 5.0 for lauric, palmitic, stearic, and oleic acids (Jukes and Schmidt 1935). All of these values are near to the values for acetic acid (4.76, see Mesmer et al. 1989), which is typical for monocarboxylic acid species that are highly soluble in water. Sue et al. (2004) obtained similar $\mathrm{p} K_{\mathrm{a}}$ values (near 4.8) for aqueous solutions of n-alkyl carboxylic acids with relatively short chain lengths between one and six.

Back and Steenberg (1950) developed methodology for determination of the $\mathrm{p} K_{\mathrm{a}}$ values of wood extractive compounds, including fatty acids having alkyl or alkenyl chain lengths as high as 18 . They found that such determinations could be carried out in aqueous solution by starting at a sufficiently high $\mathrm{pH}$ such that the compound to be analyzed is 
essentially $100 \%$ in its ionic form, i.e. a carboxylate salt. By titrating such solutions with strong acid, they determined the $\mathrm{p} K_{\mathrm{a}}$ value of abietic acid to be 7.6.

\section{Effects of adjacent ionically charged groups on $\mathrm{p} K_{a}$}

The $\mathrm{p} K_{\mathrm{a}}$ value of a carboxylic acid group will be shifted by the presence in the same compound of electron-withdrawing or electron-contributing atoms and groups, i.e. contrasting electronegativity of the neighboring atoms in the compound (Zhang et al. 2006). Such an effect can explain the relatively low $\mathrm{p} K_{\mathrm{a}}$ values (about 3.3) of carboxylic acids that are attached at an alpha position relative to an oxygen (e.g. uronic acid), which are abundant in certain hemicelluloses and their products of decomposition after pulping and bleaching (Laine et al. 1996).

\section{Multi-carboxylic Monomeric Acids}

When the compound under consideration contains other ionically charged groups, in addition to the carboxylic acid under consideration, then the neighboring group influences can be relatively large. Because such effects play a critical role in the systems to be considered in this article, some key concepts will be illustrated by using citric acid as an example.

The structure of a citric acid molecule is shown in Fig. 2. Also shown is an example of successive dissociation steps, eventually leading to a fully dissociated molecule with three negative charges. Table 1 documents results of several studies that have evaluated the $\mathrm{p} K_{\mathrm{a}}$ values for these dissociation steps. The slight differences between results obtained in different studies can reasonably be attributed to such factors as (a) advances in the quality of available instruments with the passage of time, (b) effects due to dissolved carbon dioxide from the air, and (c) calibration issues.

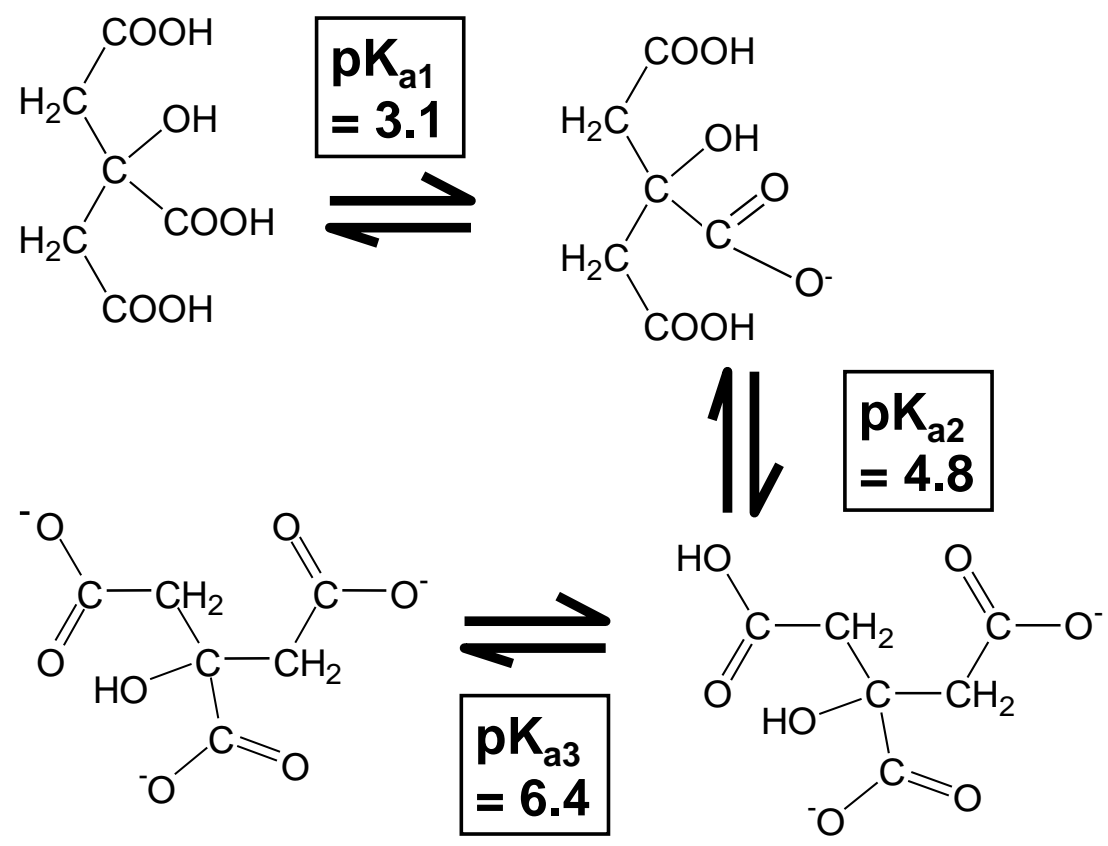

Fig. 2. Chemical structure and an example of successive dissociation steps of citric acid 
Table 1. Reported $p K_{\mathrm{a}}$ Values for the Three Dissociation Steps of Citric Acid

\begin{tabular}{|c|c|c|c|l|}
\hline Salt & $\mathbf{p} \boldsymbol{K}_{\mathrm{a}} \mathbf{( 1 )}$ & $\mathbf{p} \boldsymbol{K}_{\mathrm{a}} \mathbf{( 2 )}$ & $\mathbf{p} \boldsymbol{K}_{\mathrm{a}} \mathbf{( 3 )}$ & \multicolumn{1}{|c|}{ References } \\
\hline None & 3.08 & 4.39 & 5.49 & Hastings \& Van Slyke 1922 \\
\hline None & 3.15 & 4.77 & 6.40 & Bates \& Pinching 1949 \\
\hline None & 3.11 & 4.44 & 5.83 & Saeeduddin et al. 1996 \\
\hline None & 3.13 & 4.76 & 6.40 & Bénézeth et al. 1997 \\
\hline None & 3.13 & 4.76 & 6.40 & Crea et al. 2004 \\
\hline $0.1 \mathrm{M} \mathrm{NaCl}$ & 2.90 & 4.34 & 5.68 & Bénézeth et al. 1997 \\
\hline $0.1 \mathrm{M} \mathrm{NaCl}$ & 2.92 & 4.35 & 5.77 & Crea et al. 2004 \\
\hline $1.0 \mathrm{M} \mathrm{NaCl}$ & 2.79 & 4.08 & 5.28 & Crea et al. 2004 \\
\hline $5.0 \mathrm{M} \mathrm{NaCl}$ & 3.06 & 4.40 & 5.29 & Crea et al. 2004 \\
\hline Sat. NaCl & 2.28 & 4.32 & 5.41 & Bénézeth et al. 1997 \\
\hline
\end{tabular}

As shown in the table, each successive dissociation step for citric acid requires an increase of about $1.3 \mathrm{pH}$ units above the preceding $\mathrm{p} K_{\mathrm{a}}$ value in order to bring about dissociation of 50\% of the next carboxylic acid. The second dissociation is different from the first because one of the carboxylic acid groups is already ionized, and the presence of the ionic charge tends to suppress the dissociation of the next group. Likewise, the presence of two ionized groups nearby on the molecule further suppresses the third dissociation.

It is also apparent from Table 1 that salt addition generally decreased the observed values of $\mathrm{p} K_{\mathrm{a}}$. This can be attributed to a shielding effect of the salt ions (Stigter 1991; Hunter 2001). It is well known that salt ions in solution, depending on their concentration, decrease the Debye-Hückel length parameter, $\kappa^{-1}$, which is related to the thickness of ionic double layer effects in solution and at surfaces (Hunter 2001). Strong interactions between adjacent ionizable groups can be anticipated when they are close together relative to the value of $\kappa^{-1}$.

\section{Polymeric Carboxylic Acids}

Polymers having a multiplicity of carboxylic acid groups provide further useful examples from which to understand the effects of neighboring groups on the equilibria of dissociation. Publications have shown that the dissociation of carboxylic acid groups within polycarboxylic acid materials tends to be suppressed relative to similar separate, monomeric groups, especially in the absence of salts (Ghosh 1976; Bradna et al. 1994; Lutzenkirchen et al. 2011). With increasing salt concentration, the difference is less, which provides another example of the screening of the electrostatic effects by the ions in solution (Bradna et al. 1994; Lutzenkirchen et al. 2011). Panagiotopoulos (2009) showed that such data also can be fitted using a numerical simulation approach.

Related evidence has been found when studying the surface charges of cellulosic pulp fibers. Detailed work by Herrington and Petzold (1992a,b) showed that the dissociation of carboxylic acid groups at cellulosic fiber surfaces tends to be spread out over a wider range of $\mathrm{pH}$ than can be attributed to a single acid dissociation process, as would be represented by Eq. 4. Figure 3 compares curves reported by Herrington and Petzold (1992a) to a calculated curve for acetic acid (Mesmer et al. 1989). Since the carboxylic acid groups associated with kraft pulp fibers are mainly of one general type (Laine et al. 1996), the best explanation is that dissociation of one selected group suppresses the dissociation of similar nearby groups along the chain. 


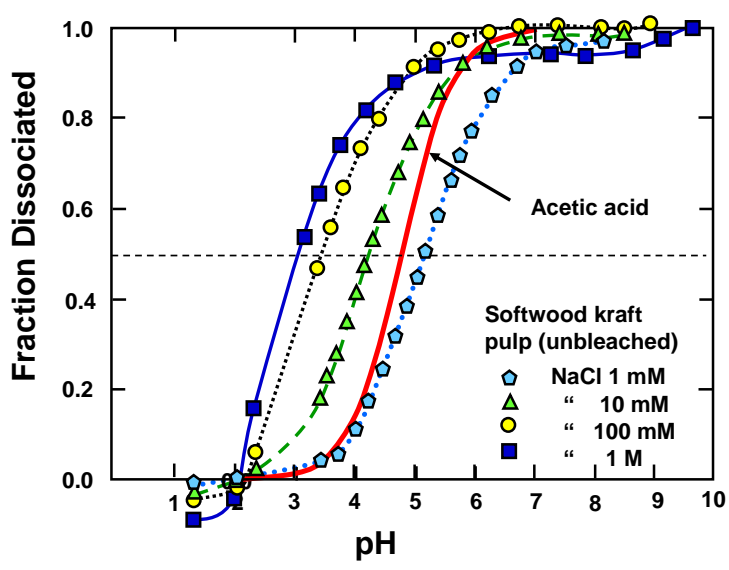

Fig. 3. Comparison of potentiometric titration curves obtained for cellulosic fiber suspensions, at different salt concentrations (Herrington and Petzold 1992a), with calculated results for acetic acid. Negative values correspond to surfaces having a net positive charge, consistent with protonation of other functional groups.

Bygrave and Englezos (1998) showed that the fitting of potentiometric titration data could be improved by simultaneous use of more than one value of $\mathrm{p} K_{\mathrm{a}}$. These authors were implicitly assuming that dissociation of some groups at the fiber surfaces makes it more difficult to dissociate subsequent carboxylic acid groups in the near vicinity. It is also worth noting that ordinary high-yield papermaking pulps will contain not only hemicellulose-type $\mathrm{COOH}$ groups, but also the carboxylic acids groups associated with any residual fatty acids and resin acids. The latter will generally have higher $\mathrm{p} K_{\mathrm{a}}$ values than the hemicellulose-type groups for two reasons. First, there are no oxygen atoms at adjacent carbons in the extractive compounds. The second reason, to be discussed in a subsequent section, is called the colloidal $\mathrm{p} K_{\mathrm{a}}$ effect.

The salt effects shown in Fig. 3 (Herrington and Petzold 1992a) are consistent with a shielding effect, which can be expected to be especially effective in cases where the ionizable groups are farther apart than when attached to adjacent carbons in a polymer chain. Budd and Herrington (1989) reported that increasing salt is able to shift the apparent $\mathrm{p} K_{\mathrm{a}}$ values of carboxylic acid groups at fiber surfaces by about two $\mathrm{pH}$ units toward lower values. It is well known that shielding effects become much greater as the distance becomes larger than $\kappa^{-1}$, the effective thickness of an electrical double layer in the system (Hunter 2001).

\section{Monolayers of Fatty Acids and their Soaps}

The science of the spreading of oleophilic films got its start with a publication by Benjamin Franklin, who spread a teaspoonful of olive oil on Derwent Lake in England, with a dramatic demonstration of the stilling of waves (Franklin et al. 1774; Binks 1991). Major breakthroughs in the field were achieved by Langmuir (1917), who was the first to demonstrate that compressed fatty acid monolayers occupy approximately the same area per molecule, independent of chain length.

Though the achievements of Langmuir continue to be greatly respected, subsequent researchers have quantified significant differences in the stability of monolayers of fatty acids and their salts, depending on such factors as chain length. Some key findings are summarized in Table 2. 
Table 2. Work Related to the Stability of Monolayer Films of Fatty Acids and their Salts as Affected by Alkyl or Alkenyl Chain Length

\begin{tabular}{|l|l|}
\hline Observation & References \\
\hline Stable films formed when chain length $(\mathrm{n})>11$. & Allara \& Nuzzo 1985 \\
\hline Fatty acid salts in Cu with $\mathrm{n}>\mathrm{8}$ were hydrophobic. & Ein-Eli 2008 \\
\hline Alkylthiols become stable when $\mathrm{n}>15$. & Broniatowski 2009 \\
\hline
\end{tabular}

As noted by Vollardt and Fainerman (2006), a compressed monolayer may contain more than one type of ordered phase, even when just one type of surface-active molecule is present. Phases and phase transitions involving condensed monolayers at interfaces have been reviewed (Kaganer et al. 1999).

When an insoluble monolayer at the water surface is subjected to sufficient pressure, within the plane of the layer, it will undergo collapse. Joos (1971) studied the relationship between $\mathrm{pH}$ and collapse pressure. Lee (2008) reviewed evidence pertaining to such collapse and concluded that it typically involves a folding mechanism. Vaknin $e t$ al. (2007) showed that folding and collapse can lead to stable bilayer and trilayer structures. Details of the layer structures were different in the presence or absence of cationic ions in the aqueous phase.

\section{Micellization}

When surface-active molecules are placed in water, one ordinarily can expect a tendency of mutual association (Zana 1996, 1997). Whenever the concentration in aqueous solution is above a level called the critical micelle concentration (CMC), the mixture will contain micelles, i.e. groups of about 7 to 64 surfactant molecules with the headgroups near the interface of the aqueous phase and with tail groups self-associating in a disorganized pattern (Zana 1997). As illustrated in Fig. 4, within each micelle the surfactant molecules will have a preferential association in which the hydrophobic tails are gathered into a predominantly hydrophobic region.

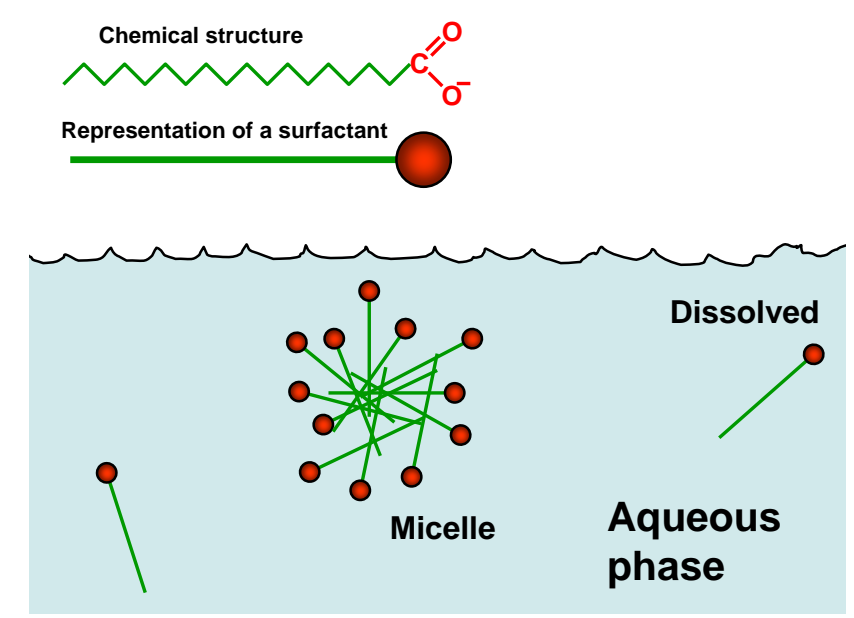

Fig. 4. Schematic description of a micelle, in which surface-active molecules are depicted as a hydrophilic headgroup and a hydrophobic tail

The hydrophilic headgroups generally will be directed outwards from each micelle towards the aqueous phase. Though forces of interaction favor the growth and regular organization of the micelles, thermal forces continually act to randomize the system. 
Though Fig. 4, for simplicity, represents the tail groups as straight sticks, molecular dynamic simulation studies predict that they will have a wide variety of randomized conformations at any moment (Zana 1997).

The CMC value corresponding to a given type of surface-active compound can be used as an indicator of the strength of mutual association among the surfactant molecules in a mixture. Thus, studies have shown a strong decreasing tendency of CMC with increasing alkyl or alkenyl chain length (Ström 2000; Brito et al. 2011; Kroflic et al. 2011). This makes sense because the free energy of mutual association increases in proportion with the chain length (Tanford 1980). Zana (1996) reviewed related literature and estimated that mutual association among dodecyl chains in a monolayer structure contributes approximately $-20 \mathrm{~kJ} /$ mole of free energy.

If there is unsaturation (i.e. a $\mathrm{C}=\mathrm{C}$ double bond) in the tail, the effect is to make the tail act as if it were about two carbons shorter, relative to the CMC expected for the fully saturated analogue (Brito et al. 2011). This makes intuitive sense based on the average shape of the molecule. A double bond, especially if it is of the cis type, will cause a persistent bend, which will decrease the average end-to-end length of the chain.

Several researchers have shown that the CMC of ionically charged surfactants tends to decrease with increasing ionic strength (Lin et al. 2005; Šarac and Bešter-Rogač 2009; Kroflic et al. 2011; Kakehashi et al. 2012). The explanation for such effects again appears to involve a shielding effect. Shielding of the electrostatic forces due to the presence of salt will reduce the importance of the ionic charges with respect to solubility of the compound.

\section{Self-assembly at Interfaces}

The term self-assembly indicates systems in which molecular components become organized in a regular, seemingly planned manner, but without the need for external control. This term becomes relevant in the case of fatty acids and their salts when one considers how they organize themselves at interfaces, in micelles, and in bubbles. Allara and Nuzzo (1985) as well as Touwslager and Sondag (1994) showed that long-chain alkanoic acids can form close-packed oriented monolayers on oxidized alumina surfaces. Touwslager and Sondag (1994) found that the degree of order within such self-assembled layers increased with increasing chain length. In other words, longer alkyl chains provided a greater tendency for self-association and ultimately tighter and more perfect monolayer films. Liascukiene et al. (2014) proposed that self-association was the key mechanism by which fatty acid addition to water in the presence of oxidized aluminum rendered such surfaces hydrophobic. Sobhana et al. (2017) recently found evidence of self-association when cellulose fibers were first treated with silver-aluminum double hydroxides, followed by addition of stearic acid a $\mathrm{pH}$ of about 10, which is sufficient to keep the compound in its soap form. Again, the resulting hydrophobic effect was attributed to self-association of the fatty acid soap molecules onto the cationic treated surfaces, forming a well-ordered monolayer with the water-hating tails pointing outwards. It has been shown that when aluminum species have been formed on the surface of pulp fibers, thus constituting a mordant, various fatty acids can then arrange themselves in a layer to provide effective hydrophobic sizing (Shimada et al. 1997).

Considerable progress has been achieved in characterizing the tightness of packing within long-chain alkyl and alkenyl chains at interfaces. Findings are summarized in Table 3 , along with some selected references. As shown, double bonds within the hydrophobic chain, especially those with cis conformation, tend to resist the tight packing of the monolayers. When the surfactant molecules have charged headgroups, such as carboxylate, 
this tends to expand the monolayer film, but such effects are opposed if the solution contains divalent cations such as calcium or magnesium ions. The situation with aluminum ions is more complex (Binks 1991), which is consistent with the dominance of different aluminum ionic species as a function of $\mathrm{pH}$ (Bottero and Fiessinger 1989; Bi et al. 2004).

Table 3. Factors Affecting the Tightness of Packing of Long-chain Fatty Acid and Related Monolayers

\begin{tabular}{|l|l|l|}
\hline Key Factor & Observation & References \\
\hline Chain length & $\begin{array}{l}\text { Increasing density with increasing } \\
\text { chain length. The orientation of fatty } \\
\text { acid chains became perpendicular to } \\
\text { the interface at high chain length. }\end{array}$ & $\begin{array}{l}\text { Tao 1993; Touwslager \& } \\
\text { Sondag 1994 }\end{array}$ \\
\hline $\begin{array}{l}\text { Decreasing density due to C=C } \\
\text { double bonds in the chain. }\end{array}$ & $\begin{array}{l}\text { Langmuir 1917; Polimeno et al. } \\
2001 ; \text { Kanicky and Shah 2002; } \\
\text { Vollhardt \& Fainerman 2006; } \\
\text { Vollhardt 2007; Sundberg et al. } \\
\text { 2009; Strand 2013 }\end{array}$ \\
\hline $\begin{array}{l}\text { Headgroup } \\
\text { repulsions }\end{array}$ & $\begin{array}{l}\text { Headgroup repulsions (especially } \\
\text { electrostatic) decrease the density. }\end{array}$ & $\begin{array}{l}\text { Adam 1921; Adam \& Miller } \\
1933 ; \text { Binks 1991; Johann et al. } \\
2001 ; \text { Polimeno et al. 2001 }\end{array}$ \\
\hline Multivalent cations & $\begin{array}{l}\text { Dense films, especially with } \mathrm{Ca}^{2+}, \text { but } \\
\text { sometimes expanded with } \mathrm{Al}^{3+} .\end{array}$ & $\begin{array}{l}\text { Goddard and Ackill 1963; Binks } \\
1991\end{array}$ \\
\hline
\end{tabular}

Fatty acids within natural samples of wood and related bioresources are invariably mixtures, containing a range of unsaturated (such as oleic, linoleic, and linolenic acids) and saturated (such as stearic acid) components, in addition to triglyceride fats and other hydrophobic compounds such as $\beta$-sitosterol (pine oil). Studies have shown that when such mixtures are collected as monolayer films, some of the component compounds may become self-segregated into separate domains (Angelova et al. 1994; Lieckfeldt et al. 1994; Johann et al. 2001; Ocko et al. 2002; Torrent-Burgués 2018).

\section{Free Energy of Association}

To account for the aforementioned effects, including micellization, the tightness of packing, and segregation of different compounds within spread monolayers, there has been progress with respect to determining the free energy of interaction associated with monolayers of fatty acids, their salts, and related compounds.

Wang et al. (2011) determined values of free energy in the range 30 to $40 \mathrm{~kJ}$ per mole of surfactant molecules, for their mutual association in micelles. Earlier, Boyd (1958) calculated the free energy of transfer from a melted fatty acid phase to a spread monolayer to be approximately $20.92 \mathrm{~kJ}$ per mole in the case of palmitic acid at room temperature. The latter value is smaller than it might be, since it does not consider a hypothetical (but unrealistic) initial state at which the molecules are individually dissolved in the aqueous solution.

It is tempting, but also potentially misleading, to attribute the free energy of association among alkyl or alkenyl chains in a monolayer to just the van der Waals components of forces (see, for instance, Wellen et al. 2017). Since the alkyl (or alkenyl) chains are nonpolar, the tendency of mutual association has been called "hydrophobic effect." There is no denying that the dispersion force (London) components of van der Waals forces act between adjacent molecules, whether charged or uncharged, polar or 
nonpolar. However, according to Tanford (1980), in fact the largest contribution to the hydrophobic effect, including the energy of association of alkyl chains, consists of hydrogen bonding. This is because the free energy of the system is minimized when hydrophobic substances are segregated, allowing more of the water molecules to be completely associated with each other, for which hydrogen bonding contributes the largest contribution of free energy. Attraction between the tails themselves is not the dominant influence. Meyer et al. (2006), reviewed experimental evidence indicating that, regardless of its origins, the hydrophobic effect is short in range $(<10 \mathrm{~nm})$.

\section{Colloidal $\mathrm{p} K_{\mathrm{a}}$}

The term "colloidal $\mathrm{p} K_{\mathrm{a}}$ " refers to the observation that the dissociation constants of long-chain fatty acids take on a different values when the molecules are associated together, especially in the absence of salt ions. This effect was apparent already in the results reported by Nyrén and Back (1958a). They reported that the $\mathrm{p} K_{\mathrm{a}}$ of lauric (C12) and myristic (C14) acids was markedly different depending on whether the determination was carried out at low concentration or high concentration of the respective fatty acids. As shown in Table 4, the $\mathrm{p} K_{\mathrm{a}}$ values were observed to increase by between 1.2 and $1.7 \mathrm{pH}$ units when increasing the concentration, thereby allowing micelles to form and govern the behavior of most of the fatty acid molecules present.

Table 4. Effects of Low vs. High Concentration of Fatty Acid on the $\mathrm{p} K_{\mathrm{a}}$ Values of Lauric and Myristic Acids

\begin{tabular}{|l|l|l|}
\hline Type of Fatty Acid & Lauric & Myristic \\
\hline $\mathrm{p} K_{\mathrm{a}}$ at low concentration & 5.3 & 6.3 \\
\hline $\mathrm{p} K_{\mathrm{a}}$ at high concentration & $\mathrm{ca} .7$ & $\mathrm{ca} .7 .5$ \\
\hline
\end{tabular}

Reported findings regarding colloidal $\mathrm{p} K_{\mathrm{a}}$ are listed in Table 5. The reported findings can be summarized as follows: The state of dissociation of the carboxylic acid groups is greatly influenced by their being held in very close proximity to each other. Thus, the observed shifts in $\mathrm{p} K_{\mathrm{a}}$ tend to be the greatest in the case of stearic acid (C18) or even longer fully saturated alkyl chains (McLean et al. 2005a; Strand 2013). Apparently 18 carbons provides sufficient free energy of interaction to overcome such factors as repulsion between the headgroups, which otherwise would tend to expand the monolayer film. As in the case of citric acid, as discussed earlier, the presence of a dissociated, and thereby charged group, will suppress the dissociation of neighboring groups, especially when they are held in such close proximity.

Results resembling a mirror image of those listed in Table 5 were reported by Matulis and Bloomfield (2001a,b), who studied long-chain aliphatic amines. Longer chains and increased concentrations both resulted in lower $\mathrm{p} K_{\mathrm{a}}$ values. Each additional methylene group resulted in a further shift of 0.6 to $0.8 \mathrm{pH}$ units of the $\mathrm{p} K_{\mathrm{a}}$. The fact that the shift was in the opposite direction from those considered in Table 5 is consistent with the opposite sign of charge, compared to the examples considered in the table, all of which involved carboxylic acids. Related work by Perger and Bešter-Rogač (2007) showed that micellization of such compounds is favored by higher chain length and by less hydrated counter-ions. 
Table 5. Reports of Distinctively High $\mathrm{p} K_{\mathrm{a}}$ Values for Close-packed Monolayers of Fatty Acids

\begin{tabular}{|c|c|c|}
\hline Variables tested & Key Findings & References \\
\hline $\begin{array}{l}\text { Concentration of the } \\
\text { fatty acid }\end{array}$ & $\begin{array}{l}\text { The } \mathrm{p} K_{\mathrm{a}} \text { of lauric acid was shifted upwards by about } \\
1.7 \text { units with increasing concentration, consistent } \\
\text { with a change from individually dissolved molecules } \\
\text { to predominantly micelles in the mixture. }\end{array}$ & $\begin{array}{l}\text { Nyrén and Back } \\
1958 \mathrm{a}\end{array}$ \\
\hline \multirow{2}{*}{ Location at interface } & $\begin{array}{l}\text { lonizable compounds tend to be less ionized when } \\
\text { present at interfaces (review article). }\end{array}$ & Binks 1991 \\
\hline & $\begin{array}{l}\text { The } p K_{\mathrm{a}} \text { values of carboxyl groups in a packed } \\
\text { monolayer were at least one } \mathrm{pH} \text { unit higher than } \\
\text { when present in the bulk of solution. }\end{array}$ & $\begin{array}{l}\text { Dhathathreyan } \\
2008\end{array}$ \\
\hline \multirow{4}{*}{ Chain length } & $\begin{array}{l}\text { The apparent } p K_{a} \text { values of medium chain fatty } \\
\text { acids was about } 6 \text {, and this rose to about } 8 \text { for a } \\
\text { higher ratio of oleic acid (having a longer chain } \\
\text { length). }\end{array}$ & $\begin{array}{l}\text { Lieckfeldt et al. } \\
1995\end{array}$ \\
\hline & $\begin{array}{l}\text { The value of } p K_{a} \text { increased from } 6.5 \text { to ca. } 9 \text { with } \\
\text { increasing chain length of fatty acids from } 8 \text { to } 16 \text {. }\end{array}$ & $\begin{array}{l}\text { Kanicky et al. } \\
2000\end{array}$ \\
\hline & $\begin{array}{l}\text { The apparent } \mathrm{p} K_{\mathrm{a}} \text { increased with increasing chain } \\
\text { length, eventually reaching a plateau at } \mathrm{pH} 9 \text { to } 10 \\
\text { for } 18 \text { carbons in the absence of salt. }\end{array}$ & $\begin{array}{l}\text { McLean et al. } \\
2005 a\end{array}$ \\
\hline & $\begin{array}{l}\text { Beyond a chain length of } 18, \text { no further increase in } \\
\text { pKa of fatty acids (in micellar solution) was } \\
\text { observed. The results were changed when resin } \\
\text { acids and triglycerides were also present. }\end{array}$ & Strand 2013 \\
\hline $\begin{array}{l}\text { Chain length, salt } \\
\text { and unsaturation }\end{array}$ & $\begin{array}{l}\text { The value of } p K_{a} \text { increased with increasing chain } \\
\text { length but fell with unsaturation. Salt addition } \\
\text { resulted in higher } p K_{a} \text {. }\end{array}$ & $\begin{array}{l}\text { Sundberg et al. } \\
2009\end{array}$ \\
\hline $\begin{array}{l}\text { Double bonds and } \\
\text { chain length }\end{array}$ & $\begin{array}{l}\text { For } \mathrm{C} 18 \text { fatty acids, the } \mathrm{p} K_{\mathrm{a}} \text { decreased from } 6.9 \\
\text { (saturated) to } 6.45 \text { (one double bond) to } 6.1 \text { (three } \\
\text { double bonds) in the presence of } 20 \mathrm{mM} \mathrm{NaSO}_{4} \text {. } \\
\text { The authors also showed effects of chain length, } \\
\text { agreeing with others. }\end{array}$ & $\begin{array}{l}\text { Pashkovskaya } \\
\text { et al. } 2018\end{array}$ \\
\hline $\begin{array}{l}\text { Pure soap addition } \\
\text { to water }\end{array}$ & $\begin{array}{l}\text { When adding pure sodium myristate }(\mathrm{C} 12) \text { to water, } \\
\text { the } \mathrm{pH} \text { rose, consistent with protonation of about } 1 \% \\
\text { of the compound. This is consistent with a tendency } \\
\text { of charge to be suppressed as a consequence of } \\
\text { micelle formation. }\end{array}$ & $\begin{array}{l}\text { Wen \& Franses } \\
2000\end{array}$ \\
\hline Salt concentration & $\begin{array}{l}\text { The pH was found to rise upon addition of salt to a } \\
\text { dispersion of spruce wood components. This is } \\
\text { consistent with deprotonation of fatty acids or other } \\
\text { species due to stabilization of the ionic forms as a } \\
\text { result of shielding effects. }\end{array}$ & $\begin{array}{l}\text { Örså et al. 1997; } \\
\text { MacNeil et al. } \\
2011\end{array}$ \\
\hline Salt addition & $\begin{array}{l}\text { Addition of small amounts of salt reduced the } \\
\text { colloidal } p K_{\mathrm{a}} \text { effect. Lower values of } \mathrm{p} K_{\mathrm{a}} \text { were } \\
\text { obtained in the presence of salt, consistent with a } \\
\text { reduced influence of adjacent charged groups. }\end{array}$ & $\begin{array}{l}\text { Wellen et al. } \\
2017\end{array}$ \\
\hline
\end{tabular}

\section{Multi-valent Counter-ion Effects}

As shown in Fig. 5, the presence of multivalent ions in aqueous solution has been shown to have profound effects on the state of dissociation of carboxyl groups of stearic acid (Aveyard et al. 1990; Binks 1991). When evaluated at a concentration of $0.1 \mathrm{mM}$, the aluminum ions had the greatest effect in decreasing the effective value of $\mathrm{p} K_{\mathrm{a}}$ to about 3.5. Although the trivalent aluminum ion $\left(\mathrm{Al}^{3+}\right.$ or more formally as $\left.\mathrm{Al}\left(\mathrm{H}_{2} \mathrm{O}\right)_{6}{ }^{3+}\right)$ is dominant in 
highly acidic solutions, one can expect oligomeric aluminum species, sometimes having a very high valence of +7 , to predominate at somewhat higher $\mathrm{pH}$ values (Bottero and Fiessinger 1989; Bi et al. 2004). A very high strength of complexation of such a multivalent cationic species with the carboxylate groups is consistent with stabilization of the carboxylate form at exceptionally low $\mathrm{pH}$. Indeed, aluminum has been found to complex strongly with the $\mathrm{OH}^{-}$ion (Guan et al. 2007). Thorium ions in solution have a valence of +4 , which explains their high ability to decrease the value of $\mathrm{p} K_{\mathrm{a}}$, as shown in Fig. 5 . Calcium ions, with a positive valence of 2 , decreased the $\mathrm{p} K_{\mathrm{a}}$ by about three $\mathrm{pH}$ units compared to a salt-free system (shown at the far right in Fig. 5). Sodium chloride, which was evaluated at a much higher concentration than the other compounds, also decreased the $\mathrm{p} K_{\mathrm{a}}$ value in comparison to the salt-free system. These results have high relevance to papermaking systems, in light of the very common usage of aluminum sulfate and related additives during papermaking (Strazdins 1989a). The high valence of the oligomeric aluminum species interacting with the densely packed charged head-groups of fatty acid soap suggests a strong and relatively irreversible complexation (Kubicki et al. 1999).

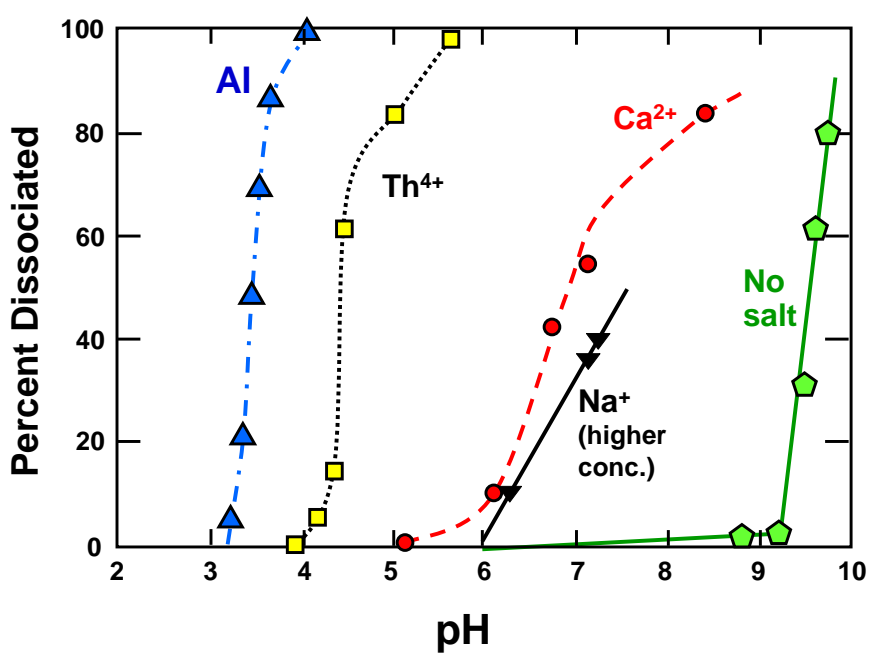

Fig. 5. Effects of the presence of different cations in aqueous solution on the dissociation of carboxylic acid groups of stearic acid in spread monolayer films (figure redrawn from Aveyard et al. 1990)

\section{Dimerization of carboxylic acids (pre-micellization and head-to-head)}

There are three modes by which fatty acid moieties have been proposed to form stable pairs (Kanicky and Shah 2003; Vercoe et al. 2004). It appears that one such mode, if formed, is likely to have an effect on the $\mathrm{p} K_{\mathrm{a}}$ values of fatty acids. The other two modes, which can be called, respectively "pre-micellization" and "head-to-head pairing by means of hydrogen bonds," will be described next, and they are illustrated in Parts A and B of Fig. 6.

As illustrated in Part A of Fig. 6, it is logical to expect that pairs of fatty acid soap molecules, in aqueous solution well above the $\mathrm{p} K_{\mathrm{a}}$ value, might tend to pair up with their head-groups facing in opposite directions. That way, the repulsion between the negative charges would be minimized, since the charged headgroups would be relatively far apart. A structure such as that shown in Part A might be hypothesized as an initial meta-stable step leading to the formation of a micelle. Though the structure makes logical sense, there 
does not appear to be firm evidence regarding whether, and under what conditions, there are quantifiable amounts of such species present in aqueous systems.

The second mode of dimerization involves a pair of protonated carboxyl species (see Part B of Fig. 6) (Vercoe et al. 2004). Such paring could be expected to play a significant role when the protonated form of carboxylic acid is dissolved in a nonpolar solvent. In such situations, the hydrogen bonding ability of carboxylic acid groups, especially when arranged as shown, can be expected to develop persistent dimers. By contrast, in aqueous systems each of the carboxyl groups would be able to associate with the much more numerous water molecules. Thus, persistent dimers of the type shown in Part B would not be expected in aqueous systems.
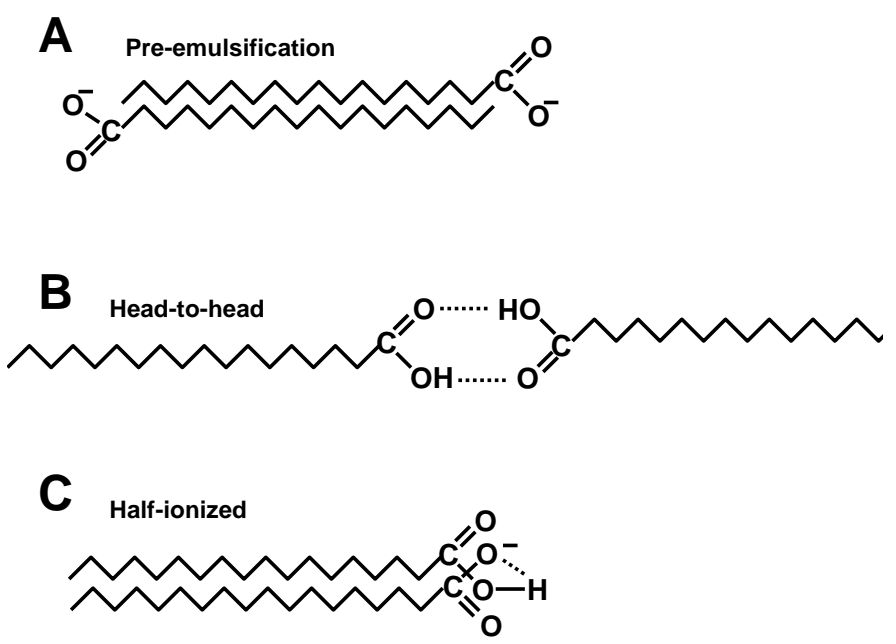

Fig. 6. Three proposed modes of dimerization of compounds related to fatty acids. A: proposed pre-micellization step at concentrations below the CMC; $\mathrm{B}$ : proposed association between pairs of protonated carboxylic acids by hydrogen bonding, especially in non-aqueous media; C: proposed association between a charged and an uncharged fatty acid moiety, especially when held in close proximity as a result of mutual association of fatty acid tail groups

\section{Association between Carboxyl and Carboxylate Groups}

Note that Part C of Fig. 6 suggests the presence of hydrogen bonding between the proton associated with one of the carboxyl groups and an oxygen belonging to the adjacent carboxylate group. Such an association has been proposed to play an important role in systems where mixtures of protonated and dissociated fatty acids are both present (Nyrén and Back 1958a; Goddard and Ackilli 1963; Goddard et al. 1966; Lieckfeldt et al. 1994; Back 2000; Kanicky et al. 2000; Kanicky and Shah 2002; Vercoe et al. 2004; McLean et al. 2005b; Dhathathreyan 2008; Strand 2013; Wellen et al. 2017).

Evidence in favor of relatively stable structures in which protonated and dissociated carboxyl groups are hydrogen bonded was presented by Binks (1991). However, the effect can be perceived more clearly if the plotted line is drawn differently from how it originally appears in the cited work. Figure 7 has been redrawn here such that the plotted line corresponds more accurately to the data points, compared to the original publication. As shown, there is a relatively horizontal section of the plotted solid line, which suggests a relatively constant composition of the monolayer within the $\mathrm{pH}$ range between about 6 and 9. Related findings have been reported by Goddard and Ackilli (1963) and Goddard et al. (1966). It has been proposed that a near-constant value of surface potential $(\Delta V)$ would 
result from a stable composition, which might be proposed to involve a 50:50 mixture of charged and uncharged fatty acid species (Kanicky and Shah 2002). Strand (2013) reported that the packing of fatty acid micelles was most dense near to the $\mathrm{p} K_{\mathrm{a}}$ value, where a $50 \%$ ionized mixture would be expected. Kanicky et al. (2000) reported that near to the $\mathrm{p} K_{\mathrm{a}}$ value there was minimum evaporation of water, maximum foam stabilization, a minimum contact angle on a plastic surface, and a maximum surface viscosity. All of these findings are consistent with a stable composition that also favors the integrity and close packing of the spread films.

The concept just described does not fit all published findings. For instance, Sanders and Spink (1955) and Betts and Pethica (1956) described a nearly linear change in the ratio of protonated to dissociated carboxyl groups in fatty acid monolayers at the water surface as the $\mathrm{pH}$ was raised in the range 4 to 8.5. In those cases there was no reported preference for a 1:1 ratio of protonated and dissociated carboxyl groups. Further work may be needed to determine whether there are other yet-unknown factors affecting such results.

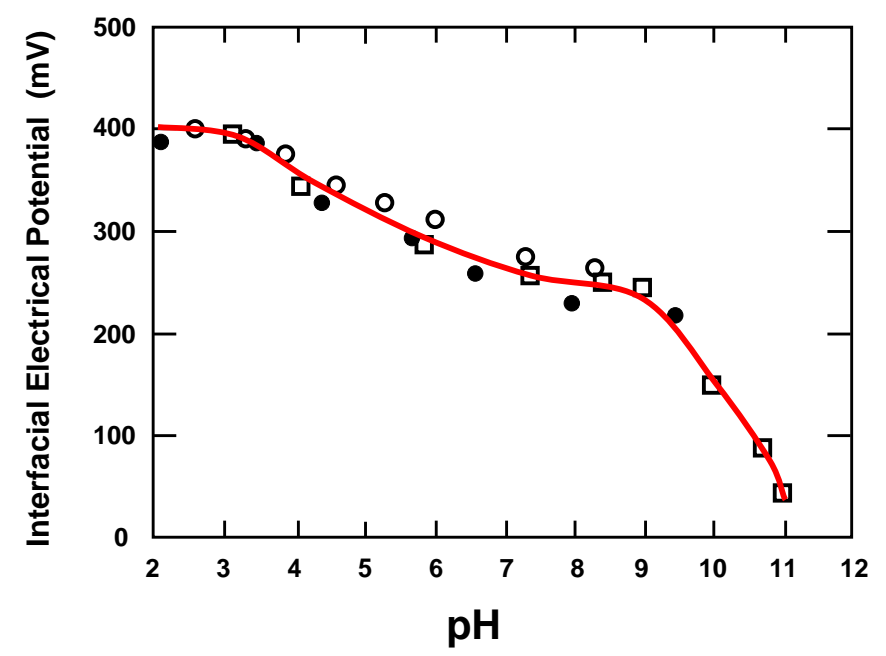

Fig. 7. Interfacial change in electrical potential across a fatty acid monolayer as a function of $\mathrm{pH}$ (replotted from Binks 1991)

\section{PITCH PROBLEMS AND CONTROL}

\section{Pitch-related Problems in Pulp and Paper Mills}

An initial motivation for writing the present review article was to better understand and help efforts to overcome practical problems of pitch deposition in pulp and paper mills. As noted in earlier review articles on the topic, some of the most effective pitch-control measures involve deposition of wood extractives onto surfaces such as fibers or talc; alternatively, the aqueous conditions can be adjusted such that the extractives will tend to remain in stable suspension (Hassler 1988; Laubach and Greer 1991; Back 2000; Hubbe et al. 2006; McLean 2008; Tanase-Opedal et al. 2011a; Richardson et al. 2012; Strand 2013).

From the perspective of a pulp and paper manufacturer, much of the challenge presented by pitch deposition problems is related to the complexity and changing composition of wood extractives entering and passing through the system. Resin acids and terpenes, which often comprise about 0.6 to $0.9 \%$ of the dry mass of conifers used for 
pulping (Fengel and Wegener 1984), are often the major component in pitch-like deposits on papermaking equipment and related spots on the paper product (Back 2000; McLean et al. 2005b; McLean 2008; Strand 2013). As noted by Back (2000) and MacNeil et al. (2011), the resin acids are generally more water-soluble but more viscous than the fatty acids. Triglyceride esters of fatty acids are especially prominent in fresh wood chips and in wood harvested in the wintertime in temperate climates (Blazey et al. 2002). With generally warmer temperatures in recent years, there has been a trend toward lower ratios of trigyleride esters to free fatty acids, even in winter months (Stack et al. 2019b). Thus, with projected continuing warming of the world's climate, one can expect there to be an increasingly prominent role played by the free fatty acids. A high ratio of triglycerides to fatty acids in wood chips often correlates with greater severity of pitch problems in pulp and paper mills (Fisher and Messner 1992; Blazey et al. 2002; Richardson et al. 2012). On the other hand, extractives that have a low ester-to-acid ratio are susceptible to deposit problems, depending on the $\mathrm{pH}$ and the presence of hardness ions in the water (Stack et al. 2019b). Recent anecdotal information from paper mills indicates that more problematic pitch deposition episodes are happening during the summer, when a greater proportion of the triglycerides have been hydrolyzed to their corresponding fatty acid form (Stack et al. $2019 b$ ). Due to their very hydrophobic nature, the triglycerides are typically present in the core of pitch emulsion droplets (Qin et al. 2004; Vercoe et al. 2004; Lee et al. 2011; Richardson et al. 2012; Strand 2013). Low-mass unsaponifiable compounds, such as $\alpha$ pinene, sometimes are not present in typical pitch particles due to their high volatility.

Figure 8, which is presented here for the first time, represents the kind of emulsion droplet that might be present in a pulp and paper facility that processes both hardwood and softwood pulps. The resin acids shown in the figure would come from the softwood, whereas the triglycerides would come from either hardwood or softwood sources.

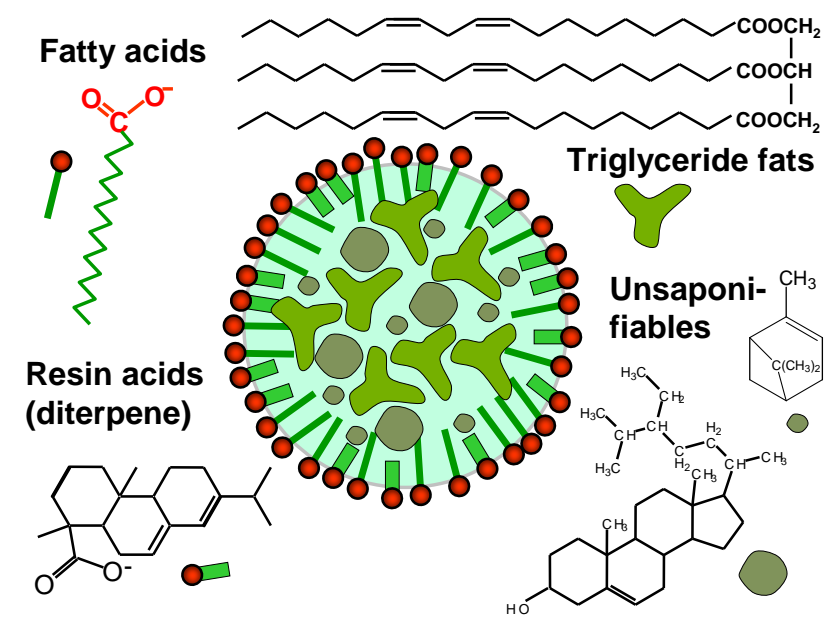

Fig. 8. Expected segregation of components within pitch droplets in a typical papermaking system, such that the more hydrophobic components are in the core and the more polar components tend to be on the outside. The unsaponifiable compounds depicted at the lower right are $\alpha$-pinene (pine oil) and $\beta$-sitosterol.

As illustrated, the fatty acids, along with resin acids, will tend to populate the outsides of pitch droplets, where they would be expected to play a big role with respect to the initial deposition of pitch onto various surfaces. Polysaccharides, i.e. hemicelluloserelated chains, often act as a stabilizer for the pitch particles in pulp and paper mill systems 
(Sihvonen et al. 1998; Back 2000; Maher et al. 2007; Strand et al. 2011a,b). However, divalent metal ions, especially $\mathrm{Ca}^{2+}$ and $\mathrm{Mg}^{2+}$, tend to reverse such stabilizing effects (Sundberg et al. 1994c; Sihvonen et al. 1998; Saarimaa et al. 2006; Strand et al. 2011a). Regression analysis by Stack et al. (2019a) showed that thermomechanical pulp mixtures with a low ester-to-acid-ratio were susceptible to destabilization in the presence of hardness ions when the $\mathrm{pH}$ was above 5.5. Some of these effects can be predicted by measuring the zeta potential, which gives an indication of whether or not the droplets will be stabilized by repulsive electrostatic forces (Back 2000).

pH shock

The immediate blame for a new episode of pitch deposition in a pulp and paper mill is often placed on some form of shock, meaning that some measurable parameter changes abruptly at some point in the process. In particular, abrupt changes in $\mathrm{pH}$ often take the blame for pitch deposits, especially when they occur at localized points in the process (Gustafsson et al. 1952; Allen 1988; Allen et al. 1998; Laubach and Greer 1991).

Confirmation of the harmful influence of upward spikes in $\mathrm{pH}$ in a mechanical pulp system were obtained in a newsprint paper mill (Allen et al. 1997; 1998). High levels of aluminum were found in the pitch deposits. Initially it was thought that the deposits might have been precipitated by the dissolution of aluminum from clay that was being used. However, the problem was eventually narrowed down to the high $\mathrm{pH}$ of the clay suspensions. The high $\mathrm{pH}$ of the clay slurry apparently brought about sufficient dissociation of the fatty acid monolayers so that the fatty acids were released into solution in the soap form. This is consistent with the findings of Ekman et al. (1990), who showed that the concentration of fatty acid moieties in solution was doubled when the $\mathrm{pH}$ of a mechanical pulp mixture was increased from 5 to 8. Sundberg et al. (1994c) noted that peroxide bleaching is another common cause of upward spikes in $\mathrm{pH}$ in mechanical pulp systems, which can lead to pitch deposit problems. The effect was attributed to the deacetylation of glactoglucomannans. Following the deacetylation, the hemicellulosic material became adsorbed onto fibers rather than playing its original role in the stabilization of pitch emulsion particles. Matulis and Bloomfield (2001a) noted that fatty acids and amines are especially susceptible to $\mathrm{pH}$ shocks. Fatty amines were found to switch from being almost completely soluble at very low $\mathrm{pH}$ to almost insoluble after titration with $\mathrm{NaOH}$ to the uncharged state. Stack et al. (2015) showed that disturbances to $\mathrm{pH}$ with an increase and then decrease back to starting $\mathrm{pH}$ resulted in a change in the nature of the extractives. Notably, it was found that an upward excursion of $\mathrm{pH}$ by itself, without being followed by a return to lower $\mathrm{pH}$, did not result in pitch deposition.

\section{Water hardness shock}

The other type of change in paper mill systems that gets blamed for pitch deposition involves addition of divalent ions. The following articles describe cases in which the presence of $\mathrm{Ca}^{2+}$ and/or $\mathrm{Mg}^{2+}$ was an essential factor in bringing about pitch deposition in pulp and paper mills (Gustafsson et al. 1952; 1954; Swanson and Cordingley 1956; Örså et al. 1977; Allen 1988; Sundberg et al. 1994b,c; Sihvonen et al. 1998; Lindström et al. 1988; Lee et al. 2011; MacNeil et al. 2011; Strand 2011a; Richardson et al. 2012). These effects might be attributed to an interaction between the divalent ions and the soap form of fatty acids (Sundberg et al. 1994c), as outlined above. Such interactions can be expected to convert the material from a soluble form to a tacky, insoluble form. For instance, Sundberg et al. (1994c) showed that an increasing concentration of $\mathrm{CaCl}_{2}$ in the range 1 to 
$10 \mathrm{mM}$ caused a mixture of colloidally stable wood pitch particles to become almost completely precipitated, leading to sedimentation. Though other compounds, such as resin acids present in their soap form, also can be involved, it is proposed here that fatty acids, due to their tendency to become soluble when the $\mathrm{pH}$ reaches a critical value, can play a trigger-type role in bringing about such deposition.

\section{Combined effect of $\mathrm{pH}$ spike and presence of divalent ions}

Based on the concepts discussed in the first part of this article, it is possible to suggest an initial explanation of pitch deposition problems brought about by $\mathrm{pH}$ shock, especially when calcium or magnesium ions are present in the aqueous phase. As shown in Fig. 9, which is published here for the first time, the mutual association among the alkyl groups of the fatty acid molecules within monolayers can be expected to keep the fatty acids in a stabilized state - either uncharged or $50 \%$ charged - at $\mathrm{pH}$ values as much as three units higher (McLean et al. 2005a; Strand 2013) than the $\mathrm{p} K_{\mathrm{a}}$ values of typical carboxylic acids (Mesmer et al. 1989). In other words, one can visualize that there may be a stable colloidal suspension present initially, as represented by the upper left part of Fig. 9. Then, a sufficiently high excursion in $\mathrm{pH}$ can be expected to result in a chaotic system, as the monolayer films at the surfaces of emulsified pitch droplets abruptly lose their stability. Freshly released fatty acid soaps immediately become vulnerable to interaction with calcium or aluminum ions, rendering them insoluble once again (Gustafsson et al. 1954; Swanson and Cordingley 1956). As shown in the figure, the released fatty acids can be expected to form hard-to-reverse complexes with multivalent ions (Kubicki et al. 1999). The composition of material, in its final macroscopic form, may be almost the same as its initial composition; however, the momentary excursion to a higher $\mathrm{pH}$ is proposed to serve as an enabling step, giving rise to a more chaotic, tackier, and larger irreversible structure of depositable extractives. The process is essentially irreversible, since the deposited material cannot be easily converted back into a colloidally dispersed, stable form.
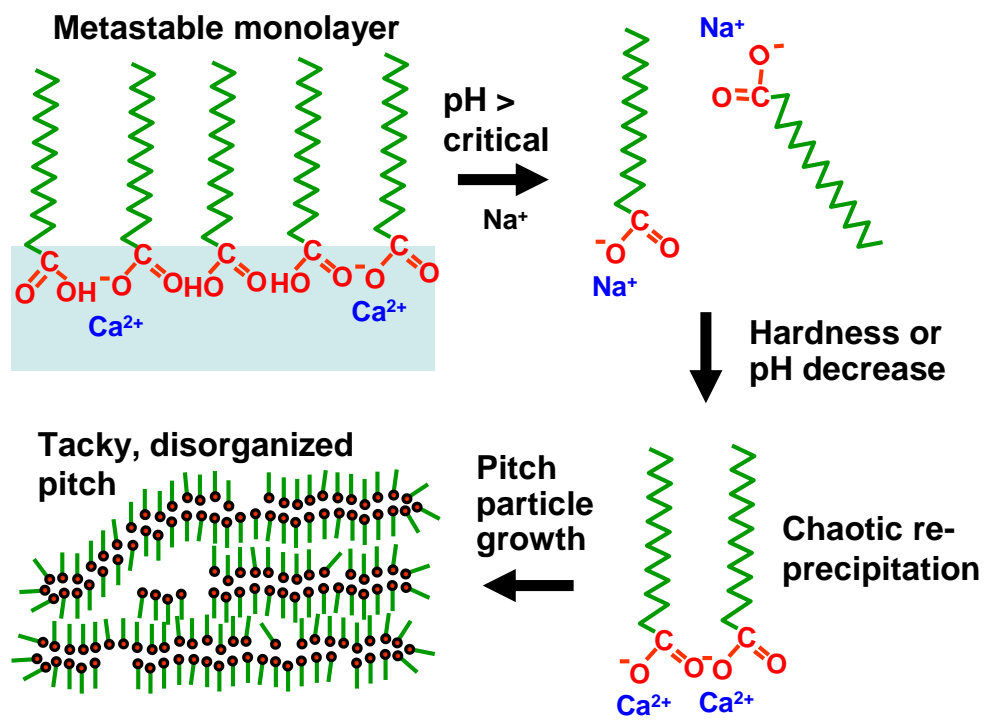

Fig. 9. Proposed mechanism to account for reported episodes of pitch deposition in paper mills initiated by upward excursions of $\mathrm{pH}$ when there are divalent ions in solution 
Though the mechanism just described is generally consistent with many of the research findings already cited in this article, it does not account for all aspects of pitch deposition. In particular, it has been shown recently that effects related to hemicellulose components may overwhelm the expected influence of calcium, relative to the deposition of pitch from a peroxide-bleached thermomechanical pulp suspension (Stack et al. 2019a,b). Also, the overall tendencies of pitch deposition tend to be different depending on whether or not the pitch episodes are dominated by resin acids. Dreisbach and Michalopoulos (1989) noted that fatty acids tend to exhibit maximum deposit problem in paper mills at neutral $\mathrm{pH}$ and low temperature, whereas resin acids showed low deposition under those same conditions.

\section{Mechanical effects}

Though the chemical-based mechanism just described provides a rationale for why $\mathrm{pH}$ shock and the presence or increased level of divalent ions are often associated with pitch deposition in pulp and paper mills, mechanical factors also appear to play a significant role. Swanson and Cordingley (1956) proposed that multilayer films of the type discovered by Langmuir and Blodgett (1935) and Blodgett and Langmuir (1937) can serve as a mechanism of pitch deposition. Langmuir and Blodgett discovered that cyclic raising and lowering of the water level in a system in which there was a condensed monolayer film of stearate molecules at the air-water interface resulted in build-up of multilayer films. It was proposed by Swanson and Cordingley (1956) that in pulp and paper mills a similar effect can take place due to rhythmic lapping wave action, such as might occur at the side of a chest. The mechanism is illustrated in Fig. 10. The material built up due to such "bathtub ring" deposition would then be susceptible to re-entrainment into the papermaking process, leading to deposits onto sensitive parts of the paper machine, such as at the headbox, forming fabric, press felts, transfer rolls, and dryer can surfaces. The cited authors suggested that the relatively brittle nature of fatty acid soap films stabilized by the presence of divalent ions or aluminum ions can favor crumpling of the material, leading to the formation of a tacky, insoluble, macroscopic deposit. Indeed, work by Angelova et al. (1994) showed a highly hydrophobic nature of such multilayers.

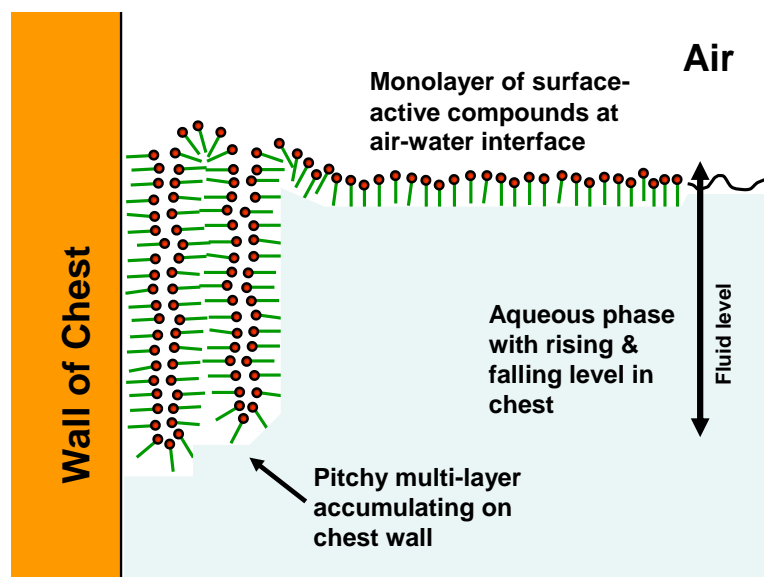

Fig. 10. Mechanism of Langmuir-Blodgett multilayer film deposition resulting from cycled raising and lowering of water level in the presence of a spread fatty acid (or mixed) monolayer film in the presence of stabilizing ions, such as divalent cations 
The mechanism shown in Fig. 10 should not be assumed to account for all pitch deposit problems in paper mills resulting from mechanical phenomena. There are other mechanical factors that likewise would be expected to promote the buildup of pitch. For example, the collapse of foam bubbles (see Fig. 11) can provide another mechanism by which monolayers of fatty acid soap molecules, sometimes stabilized by calcium or aluminum ions, can build up as multilayers (Allen 1980). Another mechanism, which is especially applicable to papermaking systems, consists of repeated contact between rotating surfaces, paper, and fabric surfaces. By such a mechanism, wood resins released from parenchyma cells can be transferred from the paper to other surfaces, leading to the filling of press felts or the creation of tacky areas on transfer rolls in the paper machine system (Hubbe et al. 2006). Also, the presence of cooler surfaces within a paper mill system might serve as the trigger for extractive materials to form deposits (Richardson et al. 2012; Stack et al. 2019a,b).

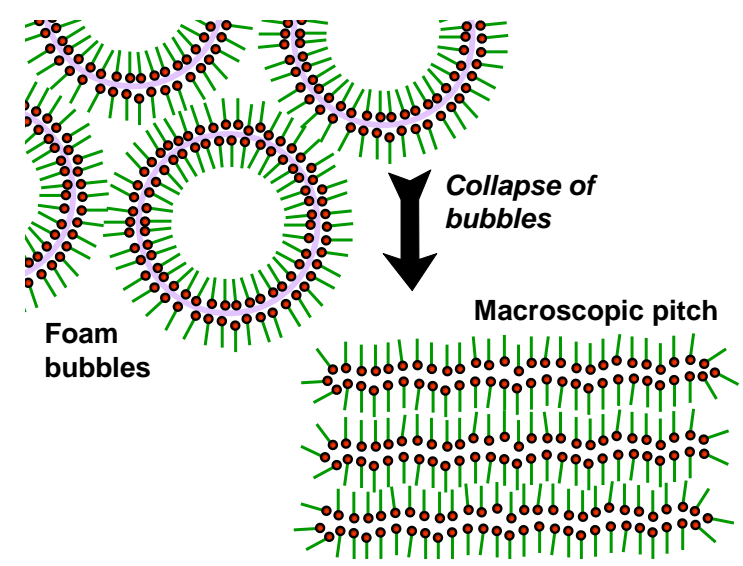

Fig. 11. Conceptual diagram suggesting how the collapse of foam bubbles can be hypothesized as a way that monolayers of fatty acids and other components of wood extractives could be transformed into multi-layer, macroscopic pitch structures

\section{Proactive Pitch Management}

Earlier review articles already have described a wide range of strategies that have shown promise in minimizing pitch deposition in a variety of different kinds of papermaking operations (Hassler 1988; Laubach and Greer 1991; Allen 2000b; Back 2000; Hubbe et al. 2006; McLean 2008). Here the focus is on looking for possible connections between the effects of such strategies and the reported tendency of the fatty acid component to form dense monolayer films, as well as the consequent shifts in $\mathrm{p} K_{\mathrm{a}}$ values and related behavior.

\section{Seasoning}

Pitch problems on paper machines have been reported to be less severe if the wood chips used for pulping have had more time to season (Laubach and Greer 1991; Gutiérrez et al. 1998). The usual explanation for these effects is that seasoning allows the progress of enzymatic action, which promotes oxidation of sterols and hydrolysis of triglycerides (Gustafsson et al. 1954; Laubach and Greer 1991; Gutiérrez et al. 1998). The latter reaction is notable in this context of this article, since it suggests that the more oleophilic ester form of fatty acids - the triglyceride fats - is typically a greater cause of pitch problems than the fatty acid soaps or protonated species that result from the hydrolysis reactions. On the 
other hand, papermaking experience has shown that abrupt substantial conversion of triglycerides to fatty acids, brought about by treatment with lipase enzymes, also can lead to severe pitch deposit problems in paper mill systems. This is an area where additional research would be helpful.

Strand et al. (2011b) reported related results dealing with the $\mathrm{pH}$ at which one-half of the fatty acids and resin acids were in the dissolved phase, i.e. the $\mathrm{p} K_{\mathrm{lw}}$ values. It was observed that the $\mathrm{p} K_{1 \mathrm{w}}$ values of fatty and resin acids were noticeably lower in pitch emulsions with a low content of triglycerides (ratio of triglycerides(TG) : resin acids(RA) : fatty acids $(\mathrm{FA})=2.0: 1.5: 1.0)$, compared to in pitch emulsions containing a high amount of triglycerides (TG:RA:FA: 5.1:1.5:1.0). This observation was accredited to formation of possible FA-RA aggregates in the water phase that were able to pass through a $0.1 \mu \mathrm{m}$ filter. It was suggested that if there is a lack of suitable surfaces for the fatty and resin acids to rest upon, they will be pushed out into the water phase, even below their $\mathrm{pKa}$. In the water phase, they should have the opportunity to be much more susceptible to pitchforming interactions than the FA/RA attached to a colloidal entity. Similar findings were later reported by Lee (2011) and Richardson et al. (2012). These authors claimed that a low ratio of triglycerides to resin and fatty acids actually altered the structure of pitch droplets, creating separate layers of resin acids and fatty acids.

\section{Deresination}

Another pro-active approach that pulp and paper manufacturers can take in an effort to overcome pitch deposition problems is to actively separate wood resins from the pulp. This can be achieved, for instance, by increasing the $\mathrm{pH}$ of high-yield pulp ahead of a washing operation (Ekman et al. 1990; Suckling et al. 1990). Suckling et al. (1990) reported the greatest increases in wood resin solubility associated with $\mathrm{pH}$ increases within the range 6 to 9 , which is consistent with the $\mathrm{p} K_{\mathrm{a}}$ values associated with fatty acids under various conditions of salt and/or multivalent ions. Presumably, the adjustment of $\mathrm{pH}$ to well above the $\mathrm{p} K_{\mathrm{a}}$ values of carboxylic acid components of the wood resins promotes their release as a micellar solution that can be washed from the fibers. The high $\mathrm{pH}$ associated with kraft pulping is likewise known to be favorable for bringing about the release of pitchlike materials from pulp fibers (Lindström et al. 1988). Kraft pulping conditions also bring about hydrolysis (converting triglyceride fats to fatty acid soaps, glycerin, and sterols), as well as other reactions leading to degradation and polymerization. The cited study noted that the released extractives may tend to precipitate again onto the pulp fibers in the final stage of brown-stock washing as a result of there being a less alkaline $\mathrm{pH}$ at that stage. Ström et al. (1990) observed the highest solubility (which can be regarded as washability) in mixtures of fatty acids and resin acids, at moderate ionic strength.

There are a few practical ways to deal with pitch-contaminated process water obtained from the washing of pulp. In an integrated pulp and paper mill, a goal is to send most of the organic solids washed from the pulp to a chemical recovery system. Another option, especially if the water contains chlorides or other species incompatible with a chemical recovery plant, is to send the filtrate from pulp washing to wastewater treatment. Alternatively, the surface-active compounds and hydrophobic matter can be separated by dissolved air or induced air flotation (Negro et al. 2005; Korpela 2006; Tanase-Opedal et al. 2011a,b; Strand et al. 2012; Zasadowski et al. 2013; Singh et al. 2016). Zasadowski et al. (2013) showed that induced air flotation, carried out under optimized conditions of $\mathrm{pH}$ and other variables, could remove $90 \%$ of the pitch-forming matter and up to $70 \%$ of pectic acids, which contribute to a high cationic demand of the furnish. Reduced $\mathrm{pH}$ conditions 
were found to be favorable for such separations (Strand et al. 2012; Zasadowski et al. 2013). At the same time, the induced air flotation did not tend to remove most of the hemicellulose content, which is known to contribute to inter-fiber bonding in paper. The flotation-based strategies take advantage of the surface-active nature of the fatty acids and some other compounds that papermakers would want removed from their process water. Because bubbles tend to be stabilized by monolayer films of surface-active molecules, including fatty and resin acids, the earlier discussions of the role of fatty acid and their soaps in such monolayers are highly relevant. Based on the earlier discussions, one can expect that the successful operation of dissolved air flotation may require stable aqueous conditions. This would include stable values of $\mathrm{pH}$, salt concentrations, and levels of multivalent cations.

\section{Additives for Control of Pitch during Papermaking}

The behavior of the fatty acid component of the wood extractives also can be considered in the light of pitch-control strategies that have been found to be effective during papermaking (Hassler 1988; Laubach and Greer 1991; Hubbe et al. 2006). One of the frequent recommendations to minimize pitch deposits in mechanical pulp systems has been to avoid excursions of $\mathrm{pH}$ above a critical value (Gustafsson et al. 1952, 1954; Allen 1988; Allen et al. 1998; Laubach and Greer 1991). Such advice is consistent with the mechanism described earlier, associated with Fig. 9. As described earlier, the mutual association within monolayers rich in fatty acids are often present in a meta-stable state, such that a spike of higher $\mathrm{pH}$, followed by a return to lower $\mathrm{pH}$ in the presence of divalent or higher-valent cations can be expected to cause an irreversible change to a much tackier and problematic pitch situation in the paper mill.

Some of the most reliable measures carried out in paper mills to address pitch deposition problems involve the use of mineral particles, such as talc (Hubbe et al. 2006; Gantenbein et al. 2010). Two tendencies appear to be responsible for the affinity of wood resin particles for various mineral surfaces. First, relatively hydrophobic minerals such as talc can be expected to preferentially collect hydrophobic materials. This is consistent with the discussion of the hydrophobic effect in the theory section of this article. Second, when mineral surfaces either have a positive charge or have been treated to make them positive (Lamar et al. 1990; Hyder et al. 1991; Bouffard and Duff 1999; Tanase-Opedal 2011a), they can collect pitch particles that are negative in charge mainly due to the presence of carboxylic acid groups.

Though the references cited in the previous paragraph generally envision a process of pitch droplets or agglomerates adsorbing onto and remaining stuck to the mineral surfaces, it makes logical sense also to expect the formation of monolayers of fatty acid soaps onto such surfaces. Self-assembly of such layers would be favored by the same circumstances that lead to such layers at air-water interfaces and at the surfaces of micelles and emulsion droplets: Though the talc surface is not as hydrophobic as air itself, it represents a surface to which there is relatively little contribution of hydrogen bonding. It follows that thermodynamics will favor structures in which the hydrophobic mineral surface is facing the non-polar part of a monolayer film. In support of the concept that the hydrophobic character of the mineral can be important, it has been shown that the beneficial effect of talc can be defeated in some systems if talc becomes covered by hydrophilic polymers (Gantebein et al. 2010).

The adsorption of extractives onto mineral surfaces is consistent with the results of flow cytometry experiments (Richardson and Grubb 2013). In the cited work, interactions 
were investigated between colloidal wood pitch and various inorganic particles (precipitated calcium carbonate, ground calcium carbonate, kaolin, and bentonite). By measuring the hydrophobicity of filler particles (hydrophilic) mixed with colloidal wood pitch (hydrophobic), it was possible to see that the mixture formed a population of intermediate hydrophobicity; i.e. the hydrophobic wood pitch happily interacted with hydrophilic filler particles in suspension. Furthermore, it was shown that these interactions could be inhibited to a certain extent by the introduction of steric stabilization to the system (the presence of water-soluble galactoglucomannans). The steric stabilization decreased the risk of collisions between pitch and filler particles and actually decreased the hydrophobicity of the resulting intermediate population.

\section{Aluminum sulfate}

Effects related to aluminum, in various forms, are of great interest in light of the widespread use of aluminum sulfate (papermaker's alum) and related additives in papermaking processes. In particular, aluminum sulfate is used sequentially with the addition of rosin size products in their emulsified acid and soap forms to render the paper hydrophobic (Strazdins 1977, 1989a; Marton 1989; Kitaoka et al. 1995, 1997). Alum is also used by papermakers to promote dewatering, to promote fine-particle retention, and to precipitate wood resins and other colloidal matter onto fiber surfaces (Strazdins 1989a). Hassler (1988) noted that alum generally has favorable effects, mitigating pitch problems, in systems where the $\mathrm{pH}$ is near to 5 , favoring the presence of positively charged ionic forms.

It has been found that alum can be effective for precipitating resinous compounds such as the hydrolysate of alkenylsuccinic anhydride (ASA) sizing agent onto the surfaces of fibers, allowing such materials to be purged from the paper machine system. Scalfarotto (1985) showed that such precipitates tended to be less tacky in comparison to the corresponding precipitates resulting from interaction with calcium or especially with magnesium divalent cations. The difference is consistent with the higher valency of the alum and its related oligomers (Bottero and Fiessinger 1989; Bi et al. 2004). As a result of the higher valency, the insolubilized matter takes on a net positive charge and is attracted to the predominantly negatively charged surfaces of the fibers. Solid-like monolayer films are formed in the presence of aluminum ions, compared to divalent metal ions (Swanson and Cordingley 1956). Such a difference suggests that the precipitated material will be less tacky and less likely to cause deposition issues.

\section{High-charge cationic polymers}

Based on the strong complexing interactions observed between the soap forms of wood resins and alum, as just described, one would anticipate strong interactions also in the case of high-charge-density cationic polyelectrolytes. Indeed, such polymers have been found to be effective in some cases in addressing pitch problems in paper mill systems (Sundberg et al. 1994a; Hubbe et al. 2006; Maher et al. 2007; McLean 2008; McLean et al. 2010). However, the success of different cationic polymers in stabilizing the pitch particles and in retaining them onto fiber surfaces have been found to be very different, and there does not seem to be an easy way to predict which polymer would be effective (Maher et al. 2007; McLean 2008; McLean et al. 2010). Such diversity of effects is consistent with the role of fatty acids in suppressing transitions from one physical state (such as a fully or half-protonated monolayer film) to another state (such as chaotic breakdown of a monolayer film above a critical $\mathrm{pH}$ value). In cases where the fatty acids 
are essentially holding back a potential chaotic transition, leading to deposition of tacky material, one can expect it to be difficult to predict reliable treatments to overcome pitch deposition problems by use of different cationic polymers.

\section{Enzymatic treatments}

Over the past several years, enzymatic treatments have become increasingly used in pulp and paper systems for a variety of purposes (Hubbe et al. 2018). One such approach involves treatment of pulp slurries with lipase, an enzyme that cleaves the ester bonds in triglyceride fats, converting them into a mixture of glycerol and free fatty acids (Fisher and Messner 1992; Fujita et al. 1992). Fisher and Messner (1992) described a process in which, after the enzymatic hydrolysis of the triglycerides, the released fatty acids were extracted by treatment with $\mathrm{NaOH}$ and washing of the pulp. Fujita et al. (1992) described a simpler system in which the released fatty acids were simply left in the papermaking process; notably the net effect was a reduction in pitch problems in the case studied. Due to the potential for a variety of interactions among different wood resin moieties, metal ions, $\mathrm{pH}$ conditions, and interactions with different solids surfaces, this is a topic that merits more extensive research.

A lesser-known type of enzyme called lipoxygenase plays a key role in the shortening of the hydrophobic tails of multiply-unsaturated fatty acids and their esters, e.g. compounds that comprise linoleic and linolenic groups (Zhang et al. 2005, 2007). Work by Tayeb et al. (2017c) showed that treatment of such unsaturated fatty acids with lipoxygenase was able to shorten them. The mechanism is illustrated in Fig. 12. In related work it was shown that such treatment decreased the deposition of unsaturated fatty acids under laboratory (Tayeb et al. 2017b) and pilot plant (Tayeb et al. 2017a) conditions. Such results are consistent with a mechanism whereby the tendency of self-association of the alkyl tails - which would be weakened by this type of enzymatic treatment -contributes to the deposition tendency of the material under suitable conditions. The mechanism indicated in Fig. 12 also can be expected to occur during storage of wood chips.

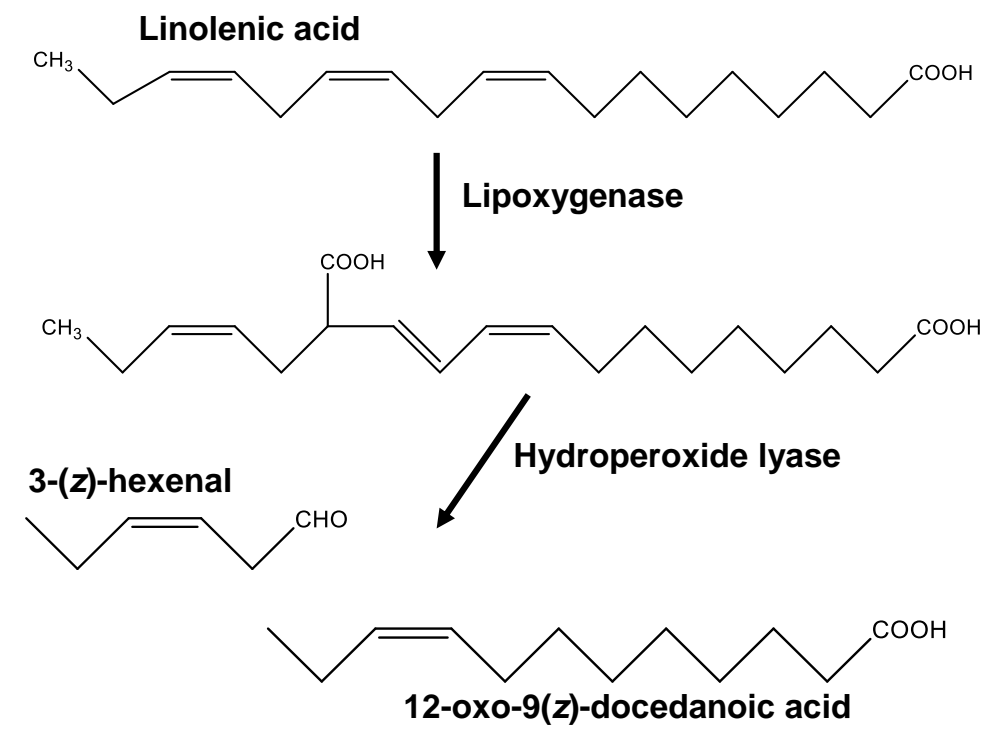

Fig. 12. Mechanism of enzymatic shortening of the tails of unsaturated fatty acids 


\section{SIZING STRATEGIES INVOLVING FATTY ACIDS}

\section{Motivation: Inexpensive and Environmentally Friendly}

There are strong motivations to consider fatty acids and their soaps as potential sizing agents for papermaking. They are widely available and low in cost. Their potential sources include not only vegetable oils, but also the alkaline pulping of wood (Jansson and Wadsborn 2007). As a compound widely present in the environment, fatty acids and their soaps are not regarded as significant environmental risks.

There are two essential characteristics of any chemical compound that is intended to act efficiently in rendering paper resistant to the spreading and permeation by aqueous fluids (Davison 1976; Dumas 1981). First, the compound needs to include a hydrophobic part. Second, it needs to have a means of becoming anchored to fibers. In the case of rosin soap sizing systems, the anchoring system is provided by carboxylate groups, which interact with aluminum ions and then help bind the precipitated material to fiber surfaces (Strazdins 1977; Marton 1989). The situation just described begs the question: Since fatty acids have a hydrophobic group, connected to a fatty acid, why have they not become more prominent was a means of imparting water resistance to paper products? Rather, as noted by Strazdins (1989b), the presence of fatty acids in the formulation hurts the effectiveness of rosin sizing. The deleterious effect of fatty acids on rosin sizing is observed especially in the case of unsaturated species, such as oleic, linoleic, and linolenic acids.

A search of the patent literature revealed only one disclosure of a paper hydrophobic sizing system based on fatty acids. Martin (1981), representing the Eastman Kodak company, claimed a system whereby the soap form of a long-chain fatty acid is precipitated by a metal ion, preferably chromium. The alkyl chain is claimed to have a length within 12 to 22 , which is consistent with development of an association tendency within a monolayer. The inventor showed that treatment of paper with such a system could inhibit subsequent staining of the paper by the next dye to which it was exposed. No related patents were found, so it is unclear whether or not the system achieved its desired ends in an effective manner.

Shimada et al. (1997) compared results for several different fatty acids, using either alum or a high-charged cationic polymer (polyallylamine) to set the size. Isocyanates were also compared, as a means to create covalent attachments so that the effects of different tails could be compared for firmly bound hydrophobic chains. The authors observed instances of poor sizing performance with $\mathrm{C} 18$ moieties, which they attributed to poor distribution of the compound within the paper sheet. They attributed the much better performance of rosin (in combination with alum treatment) to a bulky molecular structure that serves to protect the ionic linkage created by the aluminum, especially when the wetting solution was acidic due to the presence of lactic acid. In the case of fatty acids, effective sizing was generally observed at a $\mathrm{pH}$ of 4 in the presence of alum, with the requirement that the fatty acid moiety needed to have at least 10 carbon atoms in the tail. One of the unique findings was that, unlike popular sizing systems involving addition of the agent to the fiber slurry (Hubbe 2014), the treatment resulted in markedly reduced paper strength. Such an effect is consistent with the bound fatty acid layer getting in the way of potential hydrogen bond formation between the fibers in the course of drying of the paper. It is logical to expect that preparation of a waxy layer of stearic acid-type chains, especially if present as a condensed monolayer, would be detrimental to later efforts at bonding or for adhesion of the resulting paper to other surfaces. Poor adhesion and slipperiness problems have been observed in the case of sizing with alkylketene dimer, another system for 
hydrophobic sizing that involves saturated chains of stearic acid (Brungardt and Gast 1996; Hubbe 2007). Likewise, poor adhesion of xerographic toner was been reported when using a type of polyurethane with long-chain alkyl substituents during the surface-sizing of paper (Batton 1992; Hubbe 2007).

More recent efforts have been reported, obtained in the research laboratory to develop and demonstrate a sizing system based on fatty acids as a key component (Kitaoka et al. 2001; Ohno et al. 2002). The approach employed by Ohno et al. (2002) more closely resembled the practices of rosin soap sizing (Marton 1989). Thus, handsheets were prepared by treating a pulp suspension with fatty acid soaps, followed by alum. When deionized water was used to prepare the suspension, the main form of fatty acids present in the resulting paper was free fatty acids, despite the fact that the sheets were prepared in the presence of aluminum ions. When water of ordinary hardness was used in preparing the sheets, the calcium salts of the fatty acids were the main form of fatty acids in the paper, leading to hydrophobic sizing. There was also a linear correlation between the retention of fatty acids in the paper and the amount of calcium ending up in the sheets. These results suggest that a poor ability of fatty acid soaps to interact with aluminum ions in aqueous solution may be one reason why such systems have not been more successful.

Kitaoka et al. (2001) prepared base paper with aluminum sulfate, and then they dipped the sheets into a fatty acid emulsion stabilized by nonionic surfactant. The emulsion droplets had a negative charge, which was attributed to at least partial dissociation of the fatty acid to the soap form. Hydrophobic paper was obtained, especially in cases where the dipped paper was air-dried, then cured in an oven. It was also found that a highly charged cationic polymer, polyamidoamine-epichlorohydrin, could be used in place of the alum to achieve a sizing effect. These results are consistent with the self-assembly of fatty acid soap as a monolayer during drying and curing. Figure 13 provides a schematic concept for such a process. The fact that pretreatment of the pulp with alum or high-charge cationic polymer was needed for effective hydrophobic sizing is consistent with the stabilizing effect of aluminum ions on spread monolayer films (Swanson and Cordingley 1956).

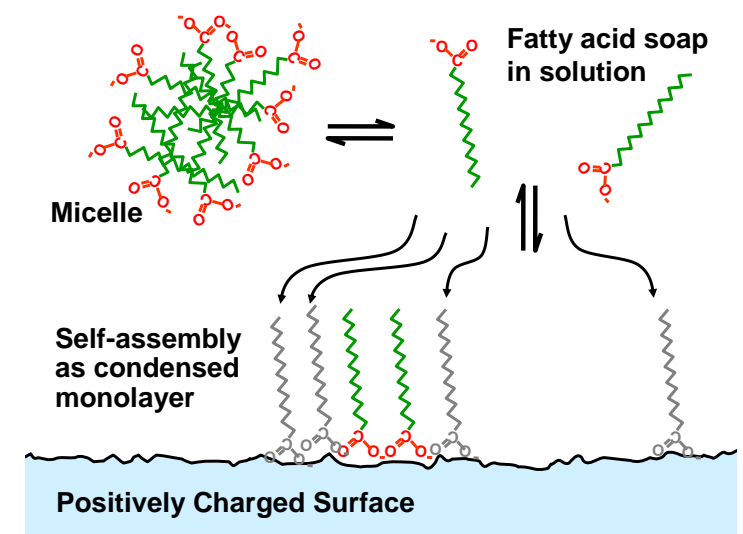

Fig. 13. Concept of self-assembly of charged surfactant molecules into a condensed layer onto an oppositely charged substrate

Success in creating hydrophobic surfaces also has been achieved for some other systems in which the surface to be hydrophobized was first provided with a strong positive ionic charge (Touwslager and Sondag 1994; Liascukiene et al. 2014). The cited authors used oxidized aluminum as a substrate. Such surfaces are known to have positive zeta 
potential at low to near-neutral $\mathrm{pH}$ values (Pedimonte et al. 2014; Liang et al. 2017). In such systems it has been shown that the amphiphilic compounds with negatively charged groups are able to self-assemble into a layer that presents a highly hydrophobic character (Liascukiene et al. 2014).

Lee and Chen (2003) showed that very hydrophobic surfaces could be created by deposition of Langmuir-Blodgett multilayers of highly ordered monolayer films. Films comprised of stearic acid gave good results, but even higher contact angles of water droplets were reached when using such compounds as octadecylamine, dipalmatoyl phosphatadyl choline, and dimyrestoyl phosphatadyl choline. Notably, the aqueous sublayer did not contain added ions, which would have been expected to be helpful in stabilizing the monolayers and helping in the preparation of Langmuir-Blodgett multilayers. The authors noted that the systems with highly ordered monolayers tended to provide the greatest resistance to wetting by water.

\section{Challenge: How to Anchor the Soap Compounds}

Notably, in the previous subsection, none of the cited studies demonstrated clear success in being able to hydrophobically treat surfaces by combining fatty acid soaps and aluminum ions, which would be the time-testing procedure by which papermakers have used rosin soap products in the so-called acidic sizing of paper (Strazdins 1977, 1989a; Marton 1989). The findings of Ohno et al. (2002) suggest that it is mainly the calcium ions, rather than any aluminum ions present, which form a stable association with spread monolayers of fatty acids in their soap form. Such results suggest a mismatch in the size of the hydrated aluminum ions relative to the position of the carboxylate groups, as dictated by their spacing within a condensed monolayer.

\section{Optimization of $\mathrm{pH}$ range for sizing using aluminum compounds}

Another kind of mismatch that helps to explain the relative lack of success that has been reported for fatty acid soap-alum sizing systems involves the species of aluminum that could be present and their dependency on $\mathrm{pH}$. As has been shown in various studies, the most effective aluminum ionic species for rosin sizing are either the $\mathrm{Al}\left(\mathrm{H}_{2} \mathrm{O}\right)_{6}{ }^{3+}$ ion that is predominant below a pH of 4 or oligomeric species such as $\mathrm{Al}^{\mathrm{VI}}{ }_{12}(\mathrm{HO})_{24} \mathrm{Al}^{\mathrm{IV}} \mathrm{O}_{4}\left(\mathrm{H}_{2} \mathrm{O}\right)_{12}{ }^{7+}$ (Bottero and Fiessinger 1989) that are typically maximized at a $\mathrm{pH}$ between 4.2 and 4.6, depending on the concentration and other factors. However, as discussed earlier, within condensed monolayers of fatty acids, the $\mathrm{p} K_{\mathrm{a}}$ values, indicating transitions between the protonated and dissociated forms of carboxyl groups, can be shifted to substantially higher values of $\mathrm{pH}$. The narrowness of the ranges of $\mathrm{pH}$ where aluminum oligomeric species are optimized (Bottero and Fiessinger 1989; Strazdins 1989a; Bi et al. 2004) in combination with the shifting of the $\mathrm{p} K_{\mathrm{a}}$ values of the fatty acids to other values outside of that range as a result of the self-association of the alkyl and alkenyl tails groups, thus provides a further explanation why fatty acids have not emerged as a major sizing agent for the paper industry.

\section{Sizing using cationic agents other than alum}

One strategy that might be used to get around to the apparent mismatch between the suitable $\mathrm{pH}$ range for sizing with alum and the shifted and sometimes hard to predict $\mathrm{p} K_{\mathrm{a}}$ behavior of fatty acids consists of selecting a different metal having different $\mathrm{pH}$ behavior of its ionic forms. For instance, since fatty acid soaps form films readily on a copper surface (Ein-Eli 2008), one might run tests with copper ions. Likewise, since fatty acids tend to form very stable monolayer films in association with cadmium ions in an 
adjacent water phase (Chen et al. 2001), one might consider using cadmium ions, except that there would be concerns regarding its toxicity. Another option might be the chromium ion, which already has been claimed as a suitable hydrophobic sizing system for use in silver emulsion-type photographic technology (Martin 1981). The literature in these areas is very limited, and there remain to be a great many other metal systems that could be evaluated in an attempt to find a practical, reliable, and environmentally friendly hydrophobic sizing system based on fatty acid soaps and a metal-based mordant.

\section{Instability of Fatty Acid Monolayers to Molecular Overturn}

Another likely problem, which makes fatty acid layers inherently different from the highly successful rosin-alum sizing system, is the possibility that films of fatty acids might by subject to easy disruption, overturn, or dissolution. Figure 14 provides a schematic definition of what is meant here by the term "overturn". Evidence of molecular overturn was obtained by Angelova et al. (1994), who prepared Langmuir-Blodgett multilayers from long-chain fatty esters. Surprisingly, contact angle experiments yielded essentially the same results irrespective of whether the outermost molecular layer was inward-facing or out-ward facing. The cited authors concluded that regardless of how the multilayers had been prepared, the molecules re-equilibrated themselves when exposed to a droplet of water. Graber et al. (2009) reported similar effects of time on the degree of hydrophobicity of soil that had become present due to an interaction of fatty acids and calcium, which served as a bridge to anionic sites on solid particles in the soil. Chen et al. (2001) concluded that fatty acid films were relatively unstable to molecular overturn based on observations of large differences in advancing and receding contact angles versus a water phase exposed to a Langmuir-Blodgett multilayer film. However, the cited authors did not consider the use of different multivalent ions, the selection of which hypothetically might be optimized to better stabilize either monolayer or multilayer films.

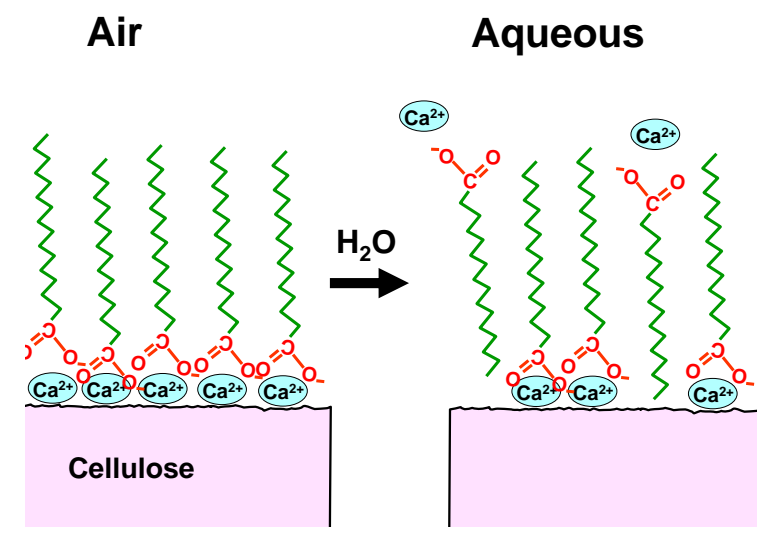

Fig. 14. Concept of "molecular overturn" when a weakly anchored surface-active monolayer is wetted by water

Györvary et al. (1996) observed that multilayer films of fatty acid stabilized by cadmium (II) and terbium (III) ions lost their water-repellent character when the $\mathrm{pH}$ was raised within the range from 5.4 to 6.7. These observations are consistent with a tendency of fatty acid molecules to become more soluble upon their dissociation to the soap form when the $\mathrm{pH}$ is raised above the $\mathrm{p} K_{\mathrm{a}}$ value (Christodoulou and Rosano 1968; Örså et al. 1997; Sundberg et al. 2009). Treatment with relatively high levels of $\mathrm{NaOH}$ would tend 
to ion-exchange the $\mathrm{Na}^{+}$ion in place of multivalent metal ions that would be needed to achieve stabilized monolayer films.

\section{Implications for Reactive Sizing Agents}

Reactive sizing agents, such as alkenylsuccinic anhydride (ASA) and alkylketene dimer (AKD) have a completely different (covalent) mode of attachment to cellulosic fiber surfaces, and they differ from fatty acids in not having any carboxylic acid groups. But on the other hand, these reactive sizing agents resemble fatty acids with respect to the hydrophobic tails groups, and it appears that some of the same issues discussed in the first main section of this article also are relevant for the reactive sizing agents and their performance.

One of the interesting contrasts between ASA and AKD is that the commercially successful ASA products have carbon chains often in the range 20 to 24 (Gess and Rende 2005; Hubbe 2007), whereas AKD is typically prepared with stearic acid chains, i.e. C18. The differences are highlighted in Fig. 15. There may be a variety of contributing factors to explain such differences; however, it should be noted that ASA typically includes a double bond within the chain (Dumas 1981; Hubbe 2007). As noted earlier, the presence of a double bond (especially in the cis conformation) tends to make the chain perform as if it were about two carbons shorter due to the kinking effect (Brito et al. 2011). Accordingly, it is reasonable to expect that the optimum length of such a chain in ASA would be somewhat longer than that present in AKD.

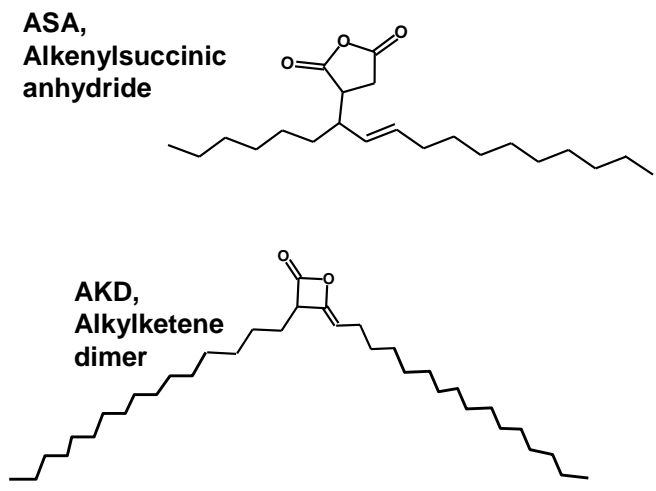

Fig. 15. Molecular structures of alkenylsuccinic anhydride (ASA) and alkylketene dimer (AKD) sizing agents

Another aspect of the two major reactive sizing systems that deserves reexamination in the light of issues considered in this article is whether the effectiveness of ASA and AKD as sizing agents depends on a mechanism in which the alkyl tails remain self-associated, as condensed monolayers, even in the finished paper. Previously it had been sometimes thought that maybe the alkyl tails somehow maximized their influence by being able to "sweep" a wider area on the fiber surface, while still remaining tethered by a covalent attachment to the fiber. But given all of the evidence presented in this article regarding a strong effect of mutual association of such groups, such a sweep model is hard to accept. Another advantage of attributing the effectiveness of AKD at least in part to mutual association of alkyl groups is that it helps to explain why AKD is such an effective sizing agent despite its well-known low reactivity (Dumas 1981; Roberts and Garner 1985; Lindström and Söderberg 1986; Ödberg et al. 1987; Brungardt 1997; Isogai 1999). For 
instance, it has been shown that paper that has been sized with AKD often contains relatively large portions of unreacted AKD (Roberts and Garner 1985; Bottorf and Sullivan 1993; Bottorf 1994). The fact that nevertheless such paper can be highly hydrophobic is consistent with an understanding that even a minority of covalent attachments to the fibers may be sufficient due to the fact that the mutual association between adjacent alkyl chains will end to hold the hydrophobic layer together and well oriented (Lindström and Söderberg 1986). The concept is illustrated in Fig. 16. The figure is drawn such that there are three ASA molecules that had reacted to form ester bonds with the cellulose surface (or starch adsorbed onto such a surface). But the second ASA molecule from the left in the figure is shown as the calcium salt of the hydrolyzed form of ASA. It is hypothesized that self-association within a condensed monolayer with sufficiently long alkyl chains will tend to hold such a structure together at a fiber surface in sized paper even if some of the molecules are not covalently bound to the surface.

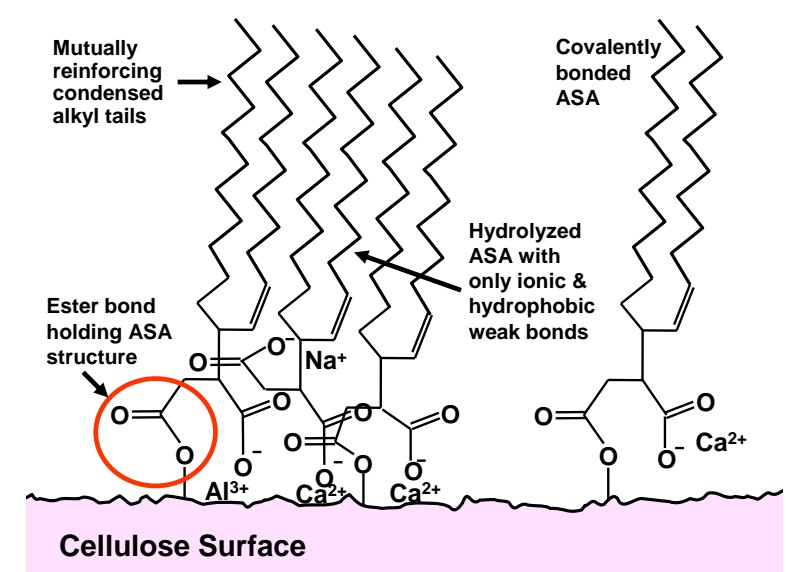

Fig. 16. Concept of hydrophobic sizing, involving ASA sizing agent, wherein the hydrophobic effect can be attributed, at least in part, to condensed, oriented monolayers in which the alkyl chains are facing outwards from the paper surface

It has been noted that when AKD is prepared with unsaturated fatty acid moieties, the resulting size paper is less slippery, which can be an issue at higher levels of treatment with ordinary AKD (Brungardt and Zhang 1999; Karademir et al. 2004). However, the effectiveness of the alkenylketene dimer (AeKD) thus formed has been found to be lower than that of regular AKD in bringing about hydrophobization, thus requiring a higher dosage to be used (Brungardt and Zhang 1999). These results provide further support for the concept introduced earlier that double bonds in the hydrophobic chain shorten its effective length (Brito et al. 2011). In addition, by making the monolayer film less solidlike, the material is less waxy and does not reduce the coefficient of friction of paper to the extent that AKD can when used at relatively high levels.

The need for further research is highlighted by some contradictory results provided by Smith (1999), who studied the effect of different positions of the double bond in ASA. Surprisingly, the cited author found that the best sizing was achieved when the double bond was centrally located in the ASA, where it would be expected to create a bend in the chain. Less efficient sizing was observed when the double bond was at the end of the alkene used in the ASA synthesis, which would be expected to yield a single straight chain alkyl tail. 


\section{BROADER IMPLICATIONS OF ALKYL TAIL ASSOCIATION EFFECTS}

While the applications areas that are the main focus of this review article are mainly in the field of papermaking, a couple of examples outside of that field will be covered in this section. There are two reasons to consider such information here. First, some of the reported findings may shed further light on the topics already considered with respect to pitch issues and sizing during papermaking. Second, there may be opportunities to apply what has been learned from papermaking systems to achieve benefits in broader applications.

\section{Soil Wettability}

In the field of soil science, Graber et al. (2009) showed that interactions involving fatty acid moieties make a significant contribution to rendering certain soil specimens hydrophobic. Consistent with other findings already considered in this article, calcium ions were found to play a role in anchoring fatty acid soap molecules at the soil particle surfaces. Parallel tests in which sodium salts of the fatty acids were used failed to develop hydrophobicity. The authors concluded that the calcium ions acted as bridges between the fatty acid moieties and negatively charged groups on the soil particles, including mineral particles. The rates of overturn of the fatty acids, upon addition to water, was relatively slow. Results also depended on the type of minerals constituting the soil particles.

\section{Hydrophobic Chitosan Sponges}

Yodkhum and Phaechamud (2014) prepared hydrophobic chitosan sponges by treating them with aluminum monostearate in a $2 \%$ lactic acid solution, followed by heating at $110{ }^{\circ} \mathrm{C}$ for 24 hours under vacuum, which was described as dehydrothermal treatment. Such treatment inhibited the swelling of the sponges when they were placed into water. Notably, the effect achieved anchoring that involved aluminum ions. This represents a type of result that Ohno et al. (2002) had been unable to achieve when attempting to hydrophobize cellulosic fibers using a conventional soap-sizing strategy, as used by papermakers.

\section{Flotation De-inking}

Theander and Pugh (2004) reviewed the mechanism of flotation deinking, a process that is often carried out by adding a combination of fatty acids and calcium chloride to a pulp fiber suspension. It was shown that the process involved encapsulation of the ink particles by precipitation of calcium salts of the fatty acids. The fact that the ink particles were then highly hydrophobic presumably was the explanation for a more effective association with small air bubbles, allowing the ink to be floated up to a froth layer, which was then skimmed from the water surface. This is another example in which the results can be explained by self-association among adjacent alkyl chains, tending to produce a condensed monolayer and leading to a low surface energy.

\section{Protection of Metal against Corrosion}

Ein-Eli (2008) studied the use of alkylcarboxylate salts as corrosion-inhibiting agents for copper. Effectiveness was found to increase with increasing alkyl chain length in the range from 3 to 12 carbons. The protective films were found to contain copper carboxylate compounds. The films prevented aggressive ions from being able to access the underlying copper. These results are consistent with two aspects that appear to be 
important for the behavior of fatty acids in papermaking system. The findings confirm both the potential anchoring role of divalent metal species and the tendency of long alkyl chains to form dense, contiguous monolayers capable of serving as a hydrophobic barrier.

\section{Superhydrophobic Systems with Fatty Acids}

The topic of superhydrophobicity, with application to papermaking systems, was reviewed by Song and Rojas (2013). The term superhydrophobic implies that water droplets on such a surface will have a contact angle of at least 150 degrees and a sliding angle less than 10 degrees. Essential steps in creating a superhydrophobic system are (a) a high degree of roughness, including nano-scale roughness, and (b) hydrophobic treatment of the surface (Hubbe et al. 2015). The latter treatment generally has to be sufficient such that a very smooth surface, after subjected to the treatment, would have a contact angle of water greater than 90 degrees. Badre et al. (2007) showed that such results could be achieved in a system comprising zinc chloride solution and stearic acid. The deposition system, involving electrochemical deposition, gave rise to nano-rods at the treated surface. Sobhana et al. (2017) achieved superhydrophobicity on cellulose fibers by a combination of stearic acid and a double hydroxide. The latter was prepared from equimolar mixtures of silver and aluminum nitrates at various concentrations, where the $\mathrm{pH}$ was controlled to 10. The superhydrophobic effect required that the mixing of ingredients take place in situ, meaning that the fibers were present during the combining step. Addition of the premixed stearate after reacting with the silver and aluminum ions failed to produce hydrophobic surfaces. Again these results are consistent with the fussy nature of pitch deposition, as described earlier, being dependent on the sequences of events and often involving nonequilibrium transition states and outcomes.

\section{Test Method Development for $\mathrm{p} K_{\mathrm{a}}$ Values}

There are various potential or existing test methods that can be implemented based on the self-association of long-chain fatty acid moieties. Fu et al. (1998) stated that electrophoretic mobility could be used as a way to get information about the $\mathrm{p} K_{\mathrm{a}}$ values of fatty acids. The cited authors determined the $\mathrm{p} K_{\mathrm{a}}$ values of fatty acid analogues having chain lengths within the range $\mathrm{C} 1$ to $\mathrm{C} 10$, and all of them (except for some chlorinated compounds) had $\mathrm{p} K_{\mathrm{a}}$ values between 4.7 and 5.0. In other words, they did not find any evidence of a colloidal $\mathrm{p} K_{\mathrm{a}}$ effect. These results are in disagreement with the findings of Lieckfeldt et al. (1995) and Kanicky et al. (2000), both of which indicated a strong shift of the $\mathrm{p} K_{\mathrm{a}}$ value to substantially higher values with alkyl chain lengths of 8 or more. It is notable, however, that the quantity that Fu et al. (1998) were measuring was zeta potential, not $\mathrm{p} K_{\mathrm{a}}$ itself. It appears that either the assumptions or the theory developed in the cited work merit re-examination.

\section{CONCLUDING REMARKS}

As stated at the outset of this review article, a goal was to focus on the role of selfassociation among the alkyl or alkenyl tails of fatty acids. Such associations can provide a window by which to try to gain additional understanding of phenomena taking place in papermaking systems. Such phenomena can include pitch deposition in paper mills, challenges related to the potential usage of fatty acids in hydrophobic treatments of surfaces, and some other related applications. The nature of papermaking systems is 
complicated, involving multiple surface-active compounds present simultaneously, as well as poorly characterized mixtures of metal ions, varying $\mathrm{pH}$ levels, various temperatures, and a range of different contact times and orders of addition. It follows that it would be unrealistic to expect that focus on the fatty acids - which are often a relatively minor component of wood resins present in such systems - would provide easy explanations of all observed phenomena. Nevertheless, the work cited in this review suggests that the tendency of self-association among the fatty acids can help lead to a more integrated understanding of the role that fatty acids play in such systems.

On the topic of pitch deposition, concepts related to self-association of fatty acid groups help explain, first of all, why the $\mathrm{p} K_{\mathrm{a}}$ values of fatty acids, when measured in the absence of salt and at sufficiently high concentration to lead to micelle formation, are two or three $\mathrm{pH}$ units higher than such acids as acetic acid, depending on experimental details. Suppression of dissociation within condensed layers of fatty acids can explain situations in which the fatty acids are sometimes released in a chaotic fashion when the $\mathrm{pH}$ momentarily exceeds a hard-to-predict critical value. Once such monolayer film structures are broken, the freed-up fatty acid soap molecules are susceptible to interaction with divalent metal ions, such as $\mathrm{Ca}^{2+}$, often leading to deposit problems. Alternatively, when fatty acid soaps layers are present at the water surface or at the surfaces of foam bubbles, wave action at solids surfaces or breakage of foam can lead to crumpling or folding of the monolayers, which provides a mechanism for generation of thicker and even macroscopic particles of tacky pitch.

Similar considerations help to explain the fussy nature of fatty acids with respect to trying to make them function as a hydrophobic sizing agent for paper. Evidence suggests that the aluminum ion - which papermakers usually rely upon when attempting to develop hydrophobicity with soap materials - do not interact strongly with fatty acids under papermaking conditions. This is possibly due to the manner in which the carboxylic acid head-groups are held close together in monomolecular films. In addition, the colloidal $\mathrm{p} K_{\mathrm{a}}$ effect means that the $\mathrm{p} K_{\mathrm{a}}$ values of the fatty acids may be outside of the range in which the aluminum species will have a cationic charge. It is possible, as an alternative approach, to generate hydrophobicity on surfaces that have been rendered cationic, followed by selfassembly of fatty acid soap molecules onto those surfaces. But such a strategy has so far failed to become popular among paper technologists.

Regardless of all the challenges associated with fatty acids present in papermaking systems, it remains true that fatty acids are relatively inexpensive, widely available, and environmentally friendly. Thus, there continues to be a strong motivation for papermakers to find a more valuable use for this material. Value-added uses for various extractive compounds would justify greater efforts at their removal before entering the papermaking system as a contaminant, where it tends to complicate efforts to deal with pitch deposition. For instance, the fatty acids could be used to hydrophobize surfaces pretreated by suitable cationic agents or metals having the right characteristics to serve as mordants for stable, well-oriented monomolecular films.

\section{ACKNOWLEDGEMENTS}

The authors wish to express their appreciation to the following volunteers who looked through an earlier version of this document and suggested corrections and needs for clarification: Dr. Piia Valto, University of Jyväskylä, Department of Chemistry, Jyväskylä, 
Finland, and Dr. Gustavo Ventorim, São Paulo State University, Câmpus Experimental de Itapeva, Brazil.

\section{REFERENCES CITED}

Adam, N. K. (1921). "The properties and molecular structure of thin films of palmitic acid on water. Part I," Proc. Royal Soc. (London) A99(699), 336-351. DOI: 10.1098/rspa.1921.0047

Adam, N. K., and Miller, J. G. F. (1933), “The structure of surface films. Part XVIII The effect of alkalinity in the underlying solution on films of fatty acids," Proc. Royal Soc. (London) A142, 401-415. DOI: 10.1098/rspa.1933.0177

Allara, D. L., and Nuzzo, R. G. (1985). "Spontaneously organized molecular assemblies. 1. Formation, dynamics, and physical-properties of $n$-alkanoic acids adsorbed from solution on an oxidized aluminum surface," Langmuir 1(1), 45-52. DOI: 10.1021/la00061a007

Allen, L. (1980). "Mechanisms and control of pitch deposition in newsprint mills," Tappi J. 63(2), 81-87.

Allen, L. (1988). "The importance of $\mathrm{pH}$ in controlling metal soap deposition," Tappi J. 71(1), 61-64.

Allen, L. (2000a). "Pitch control in pulp mills," in: E. Back and L. Allen (eds.) Pitch Control, Wood Resin and Deresination, TAPPI Press, Atlanta, pp. 265-287.

Allen, L. (2000b). "Pitch control in paper mills," in: Pitch Control, Wood Resin and Deresination, E. Back and L. Allen (eds.), TAPPI Press, Atlanta, Ch. 13, pp. 307-328.

Allen, L. H., Sennett, P. S., LaPointe, C. L., Truitt, R. E., and Sithole, B. B. (1998). "Pitch deposition in newsprint mills using certain kaolin pigments," Tappi J. 81(7), 137-138.

Allen, L. H., Sithole, B. B., LaPointe, C. L., and Truitt, R. (1997). 'Press roll pitch deposition problems associated with the use of certain clay products in newsprint manufacture," J. Pulp Paper Sci. 23(4), J157-J160.

Angelova, A., Penacorada, F., Stiller, B., Zetzsche, T., Ionov, R., Kamusewitz, H., and Brehmer, L. (1994). "Wettability, surface-morphology, and stability of long-chain ester multilayers obtained by different Langmuir-Blodgett deposition types," J. Phys. Chem. 98(27), 6790-6796. DOI: 10.1021/j100078a022

Aveyard, R., Binks, B. P., Carr, N., and Cross, A. W. (1990). "Stability of insoluble monolayers and ionization of Langmuir-Blodgett multilayers of octadecanoic acid," Thin Solid Films 188, 361-373. DOI: 10.1016/0040-6090(90)90299-S

Back, E. (2000). "Resin in suspensions and mechanisms of its deposition," in: Pitch Control, Wood Resin and Deresination, E. Back and L. Allen, (eds.), TAPPI Press, Atlanta, Ch. 6, pp. 151-183.

Back, E., and Steenberg, B. (1950). "Simultaneous determination of ionization constant, solubility product and solubility for slightly soluble acids and bases. Electrolytic constants for abietic acid," Acta Chemica Scandinavica 4, 810-815. DOI: 10.3891/acta.chem.scand.04-0810

Badre, C., Dubot, P., Lincot, D., Pauporte, T., and Turmine, M. (2007). "Effects of nanorod structure and conformation of fatty acid self-assembled layers on superhydrophobicity of zinc oxide surface," J. Colloid Interface Sci. 316(2), 233-237. DOI: $10.1016 /$ j.jcis.2007.07.046 
Bates, R. G., and Pinching, G. D. (1949). "Resolution of the dissociation constants of citric acid at 0 -degrees to 50-degrees, and determination of certain related thermodynamic functions," J. Amer. Chem. Soc. 71(4), 1274-1283. DOI: 10.1021/ja01172a039

Batton, G. L. (1992). "A papermakers guide to synthetic surface sizing agents," 1992 Papermakers Conf., TAPPI Press, Atlanta, pp. 159-167.

Bénézeth, P., Palmer, D. A., and Wesolowski, D. J. (1997). "Dissociation quotients for citric acid in aqueous sodium chloride media to 150 degrees C,' J. Solution Chem. 26(1), 63-84. DOI: 10.1007/BF02439444

Betts, J. J., and Pethica, B. A. (1956). "The ionization characteristics of monolayers of weak acids and bases," Trans Faraday Soc. 52, 1581-1589. DOI: $10.1039 / \mathrm{tf9565201581}$

Blazey, M. A., Grimsley, S. A., and Chen, G. C. (2002). "Indicators for forcasting 'pitch season', "Tappi J. 1(10), 28(2002).

Bi, S. P., Wang, C. Y., Cao, Q., and Zhang, C. H. (2004). "Studies on the mechanism of hydrolysis and polymerization of aluminum salts in aqueous solution: Correlations between the "Core-links" model and "Cage-like" Keggin- $\mathrm{Al}_{13}$ model," Coord. Chem. Rev. 248, 441-455. DOI: 10.1016/j.ccr.2003.11.001

Biermann, C. (1996). Handbook of Pulping and Papermaking, Academic Press, San Diego. DOI: 10.1016/B978-012097362-0/50026-1

Binks, B. P. (1991). "Insoluble monolayers of weakly ionising low molar mass materials and their deposition to form Langmuir-Blodgett multilayers," Adv. Colloid Interface Sci. 34, 343-432. DOI: 10.1016/0001-8686(91)80053-M

Blodgett, K. B., and Langmuir, I. (1937). "Built-up films of barium stearate and their optical properties," Phys. Rev. 51(11), 964-982. DOI: 10.1103/PhysRev.51.964

Bottero, J-.Y., and Fiessinger, F. (1989). "Aluminum chemistry in aqueous solution," Nordic Pulp Paper Res. J. 4(2), 81-89. DOI: 10.3183/npprj-1989-04-02-p081-089

Bottorf, K. J. (1994). “AKD sizing mechanism: A more definitive description," Tappi J. 77(4), 105-116.

Bottorf, K. J., and Sullivan, M. J. (1993). "New insights into the AKD sizing mechanism," Nordic Pulp Paper Res. J. 12(1), 86-95. DOI: 10.3183/npprj-1993-0801-p086-095

Bouffard, S. C., and Duff, S. J. B. (1999). "White water treatment using organically tailored heulandite minerals," Tappi J. 82(7), 178-184.

Boyd, G. E. (1958). "Energy relations in monolayer formation - The spreading of longchain fatty acids on aqueous surfaces," J. Phys. Chem. 62(5), 536-541. DOI: 10.1021/j150563a006

Bradna, P., Quadrat, O., Walterova, Z., and Snuparek, J. (1994). "Potentiometric and viscometric study of the alkalization of latex dispersions of ethyl acrylate methacrylic-acid copolymers in the presence of salt," Colloid Polym. Sci. 272(2), 191-195. DOI: 10.1007/BF00658847

Brito, R. O., Silva, S. G., Fernandes, R. M. F., Marques, E. F., Enrique-Borges, J., and do Vale, M. L. C. (2011). "Enhanced interfacial properties of novel amino acid-derived surfactants: Effects of headgroup chemistry and of alkyl chain length and unsaturation," Colloids Surf. B - Biointerfaces 86(1), 65-70. DOI: 10.1016/j.colsurfb.2011.03.017

Broniatowski, M. (2009). "Long-chain alkyl thiols in Langmuir monolayers," J. Colloid Interface Sci. 337(1), 183-190. DOI: 10.1016/j.jcis.2009.04.089 
Brungardt, B. (1997). "Improving the efficiency of internal and surface sizing agents," Pulp Paper Can. 98(12), 152-155, T480-T483.

Brungardt, C. L., and Gast, J. C. (1996). "Alkenyl-substituted sizing agents for precision converting grades of fine paper,” Proc. TAPPI Papermakers Conf., TAPPI Press, Atlanta, 297-308.

Brungardt, C. L., and Zhang, J. J. (1999). "Effect of fatty acid structure on ketene dimer performance," in: Scientific \& Technical Advances in the Internal \& Surface Sizing of Paper and Board, Pira International, Leatherhead, Surrey, UK, paper 4.

Budd, J., and Herrington, T. M. (1989). "Surface-charge and surface-area of cellulose fibers," Colloids Surf. 36(3), 273-288. DOI: 10.1016/0166-6622(89)80243-4

Bygrave, G., and Englezos, P. (1998). "Fibre charge from potentiometric titration of kraft pulp and Donnan equilibrium theory," Nordic Pulp Paper Res. J. 13(3), 220-224. DOI: 10.3183/npprj-1998-13-03-p220-224

Chen, C. Y., Chen, L. H., and Lee, Y. L. (2001). "Wettability characterization of Langmuir-Blodgett films of stearic acid," J. Chinese Inst. Chem. Eng. 32(5), 461-468.

Christodoulou, A. P., and Rosano, H. L. (1968). "Effect of $\mathrm{pH}$ and nature of monovalent cations on surface isotherms of saturated C16 to C22 soap monolayers," Advances in Chemistry Series 84, 210-234. DOI: 10.1021/ba-1968-0084.ch017

Crea, F., De Stefano, C., Millero, F. J., and Crea, F. (2004). "Dissociation constants for citric acid in $\mathrm{NaCl}$ and $\mathrm{KCl}$ solutions and their mixtures at 25 degrees C," J. Solution Chem. 33(11), 1349-1366. DOI: 10.1007/s10953-004-1046-z

Davison, R. W. (1976). “The sizing of paper,” Tappi J. 58(3), 48-57.

Dhathathreyan, A. (2008). "Dissociation constants of long-chain hydroxy fatty acids in Langmuir-Blodgett films," Colloids Surf. A - Physicochem. Eng. Aspects 318, 307314. DOI: 10.1016/j.colsurfa.2008.01.009

Dumas, D. H. (1981). "An overview of cellulose-reactive sizes," Tappi J. 64(1), 43-46.

Ein-Eli, Y. (2008). "From food preservation to surface protection: Enhanced corrosion protection by fatty acid salts," Israel J. Chem. 48(3-4), 319-332. DOI: 10.1560/IJC.48.3-4.319

Ekman, R., Eckerman, C., and Holmbom, B. (1990). "Studies on the behavior of extractives in mechanical pulp suspensions," Nordic Pulp Paper Res. J. 5(2), 96-103. DOI: 10.3183/npprj-1990-05-02-p096-103

Fengel, D., and Wegener, G. (1984). Wood. Chemistry, Ultrastructure, Reactions, de Gruyter, New York. DOI: 10.1515/9783110839654

Fisher, K., and Messner, K. (1992). "Reducing troublesome pitch in pulp mills by lipolytic enzymes," Tappi J. 75(2), 130-134.

Franklin, B., Brownrigg, W., and Farish. (1774). "XLIV. Of the stilling of waves by means of oil. Extracted from sundry letters between Benjamin Franklin, LL. D. F. R. S. William Brownrigg, M. D. F. R. S. and the Reverend Mr. Farish," Phil. Trans. Roy. Soc. 64, 445-460. DOI: 10.1098/rstl.1774.0044

Fu, S. L., Li, D. M., and Lucy, C. A. (1998). "Prediction of electrophoretic mobilities. Part 2. Effect of acid dissociation constant on the intrinsic mobilities of aliphatic carboxylates and amines," Analyst 123(7), 1487-1492. DOI: 10.1039/a800624e

Fujita, Y., Awaji, H., Taneda, H., Matsukukra, M., Hata, K., Shimoto, H., Sharyo, M., Sakaguchi, H., and Gibson, K. (1992). "Recent advances in enzymatic pitch control," Tappi J. 75(4), 117-122.

Gantenbein, D., Schoelkopf, J., Gane, P. A. C., and Matthews, G. P. (2010). "Influence of $\mathrm{pH}$ on the adsorption of dissolved and colloidal substances in a thermomechanical 
pulp filtrate onto talc," Nordic Pulp Paper Res. J. 25(3), 288-299. DOI:

10.3183/npprj-2010-25-03-p288-299

Gess, J. M., and Rende, D. S. (2005). “Alkenyl succinic anhydride (ASA),” Tappi J. 4(9), 25-30.

Ghosh, B. N. (1976). "Dissociation-constant of partly neutralized polyacrylic-acid from measurement of its $\mathrm{pH}$ at different salt concentrations," Indian J. Chem. Sec. AInorg. Bio-inorg. Phys. Theor. Anal. Chem. 14(4). 219-222.

Goddard, E. D., and Ackilli, J. A. (1963). "Monolayer properties of fatty acids," J. Colloid Sci. 18, 585-595. DOI: 10.1016/0095-8522(63)90050-3

Goddard, E. D., Smith, S. R., and Kao, O. (1966). "Monolayer properties of fatty acids. 2. Behenic acid," J. Colloid Interface Sci. 21, 320-330. DOI: 10.1016/00958522(66)90016-X

Graber, E. R., Tagger, S., and Wallach, R. (2009). "Role of divalent fatty acid salts in soil water repellency," Soil Sci. Soc. Amer. J. 73(2), 541-549. DOI: 10.2136/sssaj2008.0131

Guan, X. H., Chen, G. H., and Shang, C. (2007). "ATR-FTIR and XPS study on the structure of complexes formed upon the adsorption of simple organic acids on aluminum hydroxide," J. Environ. Sci. 19(4), 438-443. DOI: 10.1016/S10010742(07)60073-4

Gustafsson, C., Tammela, V., and Kahila, S. (1952). "On pitch troubles caused by sulphite pulp," Paperi ja Puu, Paper and Timber 34(4a), 121-126. DOI:10.1016/S0041-3879(53)80033-4

Gustafsson, C., Tammela, V., and Lindh, T. (1954). "Pitch troubles caused by sulphite pulp. II," Paperi ja Puu, Paper and Timber 36(6), 269-274.

Gutiérrez, A., del Río, J. C., González-Vila, F. J., and Romero, J. (1998). "Variation in the composition of wood extractives from Eucalyptus globulus during seasoning," Journal of Wood Chemistry and Technology 18(4), 439-446. DOI: 10.1080/02773819809349591

Györvary, E., Peltonen, J., Linden, M., and Rosenholm, J. B. (1996). "Reorganization of metal stearate LB films studied by AFM and contact angle measurements," Thin Solid Films 284, 368-372. DOI: 10.1016/S0040-6090(95)08344-8

Hassler, T. (1988). "Pitch deposition in papermaking and the function of pitch control agents," Tappi J. 71(6), 195-201.

Hastings, A. B., and Van Slyke, D. D. (1922). "The determination of the three dissociation constants of citric acid," J. Biol. Chem. 53(2), 269-276.

Herrington, T. M., and Petzold, J. C. (1992a). "An investigation into the nature of charge on the surface of papermaking woodpulps. 1. Charge/pH isotherms," Colloids Surf. 64, 97-108. DOI: 10.1016/0166-6622(92)80088-J

Herrington, T. M., and Petzold, J. C. (1992b). “An investigation into the nature of charge on the surface of papermaking woodpulps. 2. Analysis of potentiometric titration data," Colloids Surf. 64(2), 109-118. DOI: 10.1016/0166-6622(92)80089-K

Hubbe, M. A. (2007). "Paper's resistance to wetting - A review of internal sizing chemicals and their effects," BioResources 2(1), 106-145.

Hubbe, M. A. (2014). "Puzzling aspects of the hydrophobic sizing of paper and its interfiber bonding ability," BioResources 9(4), 5782-5783. DOI:

10.15376/biores.9.4.5782-5783 
Hubbe, M. A., Gardner, D. J., and Shen, W. (2015). "Contact angles and wettability of cellulosic surfaces: A review of proposed mechanisms and test strategies," BioResources 10(4), 8657-8749. DOI: 10.15376/biores.10.4.Hubbe_Gardner_Shen

Hubbe, M. A., Powell, J. S., and Delozier, G. (2018). "Enzymatic technology for wet-end implementation," in: Advances in Papermaking Wet End Chemistry Application Technologies, M. A. Hubbe and S. Rosencrance (eds.), TAPPI Press, Atlanta, Chapter 12, pp. 269-286.

Hubbe, M. A., Rojas, O. J., and Venditti, R. A. (2006). "Control of tacky deposits on paper machines - A review," Nordic Pulp Paper Res. J. 21(2), 154-171. DOI: 10.3183/npprj-2006-21-02-p154-171

Hunter, R. J. (2001). Foundations of Colloid Science, Oxford Univ. Press, New York, 2001.

Hyder, W. J., Kunkle, A. C., and Weaver, R. M. (1991). "Aluminum chlorohydrate or hydrotalcite treated kaolin clays for pitch control," US Patent 5,037,508.

Isogai, A. (1999). "Mechanism of paper sizing by alkylketene dimers," J. Pulp Paper Sci. 25(7), 251-255.

Jansson, M. B., and Wadsborn, R. (2007). "Calculation of the influence of carbonate concentration on the formation of fatty acid calcium soaps in pulp washing," Nordic Pulp Paper Res. J. 22(1), 35-41. DOI: 10.3183/npprj-2007-22-01-p035-041

Johann, R., Vollhardt, D., and Mohwald, H. (2001). "Shifting of fatty acid monolayer phases due to ionization of the headgroups," Langmuir 17(15), 4569-4580. DOI: $10.1021 / \mathrm{la} 001781 \mathrm{k}$

Joos, P. (1971). "Effect of the pH on the collapse pressure of fatty acid monolayers. Evaluation of surface dissociation constant," Bulletin des Societes Chimiqes Belges 80(3-4), 277-281. DOI: 10.1002/bscb.19710800308

Jukes, T. H., and Schmidt, C. L. A. (1935). "The combination of certain fatty acids with lysine, arginine, and salmine," J. Biol. Chem. 110(1), 9-16.

Kaganer, V. M., Mohwald, H., and Dutta, P. (1999). "Structure and phase transitions in Langmuir monolayers," Rev. Modern Phys. 71(3), 779-819. DOI: 10.1103/RevModPhys.71.779

Kakehashi, R., Shizuma, M., and Yamamura, S. (2012). "Mixed micelles containing sodium laurate: Effect of chain length, polar head group, and added salt," Tenside Surfac. Deterg. 49(6), 488-493. DOI: 10.3139/113.110221

Kanicky, J. R., Poniatowski, A. F., Mehta, N. R., and Shah, D. O. (2000). "Cooperativity among molecules at interfaces in relation to various technological processes: Effect of chain length on the $\mathrm{pKa}$ of fatty acid salt solutions," Langmuir 16, 172-177. DOI: 10.1021/la990719o

Kanicky, J. R., and Shah, D. O. (2002). "Effect of degree, type, and position of unsaturation on the $\mathrm{pKa}$ of long-chain fatty acids," J. Colloid Interface Sci. 256(1), 201-207. DOI: 10.1006/jcis.2001.8009

Kanicky, J., and Shah, D. (2003). "Effect of premicellar aggregation on the $\mathrm{pKa}$ of fatty acid soap solutions," Langmuir 19(6), 2034-2038. DOI: 10.1021/la020672y

Karademir, A., Hoyland, D., Wiseman, N., and Xiao, H. (2004). "A study of the effects of alkyl ketene dimer and ketone on paper sizing and friction properties," Appita J. 57(2), 116-120.

Kitaoka, T., Isogai, A., and Onabe, F. (1995). "Sizing mechanism of emulsion rosin sizealum systems. Part 1. Relationships between sizing degrees and rosin size or 
aluminum content in rosin-sized handsheets," Nordic Pulp Paper Res. J. 10(4), 253260. DOI: 10.3183/npprj-1995-10-04-p253-260

Kitaoka, T., Isogai, A., and Onabe, F. (1997). "Sizing mechanism of emulsion rosin sizealum systems. Part 2. Structures of rosin size components in the paper sheet," Nordic Pulp Paper Res. J. 12(1), 26-31. DOI: 10.3183/npprj-1997-12-01-p026-031

Kitaoka, T., Isogai, A., Onabe, F., and Endo, T. (2001). "Sizing mechanism of rosin emulsion size-alum systems. Part 4. Surface sizing by rosin emulsion size on alumtreated base paper," Nordic Pulp Paper Res. J. 16(2), 96-102. DOI: 10.3183/npprj2001-16-02-p096-102

Korpela, A. (2006). "Removal of resin from mechanical pulps by selective flotation: Mechanisms of resin flotation and yield loss of fibers," J. Wood Chem. Technol. 26(2), 175-186. DOI: 10.1080/02773810600704541

Kroflic, A., Šarac, B., and Bešter-Rogač, M. (2011). "Influence of the alkyl chain length, temperature, and added salt on the thermodynamics of micellization: Alkyltrimethylammonium chlorides in $\mathrm{NaCl}$ aqueous solutions," J. Chem. Thermodynam. 43(10), 1557-1563. DOI: 10.1016/j.jct.2011.05.015

Kubicki, J. D., Sykes, D., and Apitz, S. E. (1999). “Ab initio calculation of aqueous aluminum and aluminum-carboxylate complex energetics and ${ }^{27} \mathrm{Al}$ NMR chemical shifts," J. Phys. Chem. A 103(7), 903-915. DOI: 10.1021/jp983462w

Laine, J., Buchert, J., Viikari, L., and Stenius, P. (1996). "Characterization of unbleached kraft pulps by enzymatic treatment, potentiometric titration, and polyelectrolyte adsorption," Holzforschung 50(3), 208-214. DOI: 10.1515/hfsg.1996.50.3.208

Lamar, R. S., Pratt, W. E., Weber, K. E., and Roeder, R. E. (1990). "Method of reducing pitch in pulping and papermaking operations," US Patent 4,964,955.

Langmuir, I. (1917). "The constitution and fundamental properties of solids and liquids. II. Liquids," J. Amer. Chem. Soc. 39, 1848-1906. DOI: 10.1021/ja02254a006

Langmuir, I., and Blodgett, K. B. (1935). "Über einige neue Methoden zur Untersuchung von monomolekularen Filmen," Kolloid-Zeitschrift 73(3), 257-263. DOI: 10.1007/BF01428777

Laubach, G. D., and Greer, C. S. (1991). "Pitch deposit awareness and control," Tappi J. 74(6), 249-252.

Lee, K. Y. C. (2008). "Collapse mechanisms of Langmuir monolayers," Ann. Rev. Phys. Chem. 59, 771-791. DOI: 10.1146/annurev.physchem.58.032806.104619

Lee, R. (2011). “The stability of wood resin colloids in paper manufacture," Ph.D. thesis, University of Tasmania, Hobart, Tasmania, Australia.

Lee, R., Garnier, G., Lewis, T., Richardson, D., Van de Ven, T. G. M., and Stack, K. (2011). "Pitch deposition at the solid-liquid interface: Effect of surface hydrophobicity/hydrophilicity and cation specificity," Colloids Surf. A Physicochem. Eng. Aspects 388, 84-90. DOI: 10.1016/j.colsurfa.2011.08.019

Lee, Y. L., and Chen, C. Y. (2003). "Surface wettability and platelet adhesion studies on Langmuir-Blodgett films," Appl. Surf. Sci. 207, 51-62. DOI: 10.1016/S01694332(02)01235-7

Liang, L., Wang, L. G., Nguyen, A. V., and Xie, G. Y. (2017). "Heterocoagulation of alumina and quartz studied by zeta potential distribution and particle size distribution measurements," Powder Technol. 309, 1-12. DOI: 10.1016/j.powtec.2016.12.054

Liascukiene, I., Steffenhagen, M., Asadauskas, S. J., Lambert, J. F., and Landoulsi, J. (2014). "Self-assembly of fatty acids on hydroxylated Al surface and effects of their 
stability on wettability and nanoscale organization," Langmuir 30(20), 5797-5807. DOI: 10.1021/la404756y

Lieckfeldt, R., Villalaín, J., Gómez-Fernández, J.-C., and Lee, G. (1994). "Influence of oleic acid on the structure of a mixture of hydrated model stratum-corneum fatty acids and their soaps," Colloids Surf. A - Physicochem. Eng. Aspects 90(2-3), 225234. DOI: 10.1016/0927-7757(94)02919-9

Lieckfeldt, R., Villalaín, J., Gómez-Fernández, J.-C., and Lee, G. (1995). “Apparent pKa of the fatty acids within ordered mixtures of model human stratum corneum lipids," Pharm. Res. 12(11), 1614-1617. DOI: 10.1023/A:1016280714593

Lin, B., McCormick, A. V., Davis, H. T., and Strey, R. (2005). "Solubility of sodium soaps in aqueous salt solutions," J. Colloid Interface Sci. 291(2), 543-549. DOI: 10.1016/j.jcis.2005.05.036

Lindström, M., Ödberg, L., and Stenius, P. (1988). "Resin and fatty acids in kraft pulp washing: Physical state, colloid stability and washability," Nordic Pulp Paper Res. J. 3(2), 100-106. DOI: 10.3183/npprj-1988-03-02-p100-106

Lindström, T., and Söderberg, G. (1986). "On the mechanism of sizing with alkylketene dimers. Part 1. Studies on the amount of alkylketene dimer required for sizing different pulps," Nordic Pulp Paper Res. J. 1(1), 26-42. DOI: 10.3183/npprj-1986-0101-p026-033

Lutzenkirchen, J., van Male, J., Leermakers, F., and Sloberg, S. (2011). "Comparison of various models to describe the charge-pH dependence of poly(acrylic acid)," J. Chem. Eng. Data 56(4), 1602-1612. DOI: 10.1021/je101253q

MacNeil, D., Sundberg, A., Vahasalo, L., and Holmbom, B. (2011). "Effect of calcium on the phase distribution of resin and fatty acids in pitch emulsions," J. Dispersion Sci. Technol. 32(2), 269-276. DOI: 10.1080/01932691003659270

Maher, L., Stack, K. R., McLean, D. S., and Richardson, D. E. (2007). "Adsorption behaviour of cationic fixatives and their effect on pitch deposition," Appita J. 60(2), 112-119, 128.

Martin, T. W. (1981). "Color imaging device having a color filter array using a metal salt of a long-chain fatty acid as a barrier," US Patent 4,355,087.

Marton, J. (1989). "Mechanistic differences between acid and soap sizing," Nordic Pulp Paper Res. J. 4(2), 77-80. DOI: 10.3183/npprj-1989-04-02-p077-080

Matulis, D., and Bloomfield, V. A. (2001a). "Thermodynamics of the hydrophobic effect. 1. Coupling of aggregation and $\mathrm{p} K_{\mathrm{a}}$ shifts in solutions of aliphatic amines," Biophys. Chem. 93(1), 37-51. DOI: 10.1016/S0301-4622(01)00207-1

Matulis, D., and Bloomfield, V. A. (2001b). "Thermodynamics of the hydrophobic effect. II. Calorimetric measurement of enthalpy, entropy, and heat capacity of aggregation of alkylamines and long aliphatic chains," Biophys. Chem. 93(1), 53-65. DOI: 10.1016/S0301-4622(01)00208-3

McLean, D. S. (2008). A Study of Wood Resin and Cationic Water Soluble Polymers: Wood Pitch Fixatives, PhD Dissertation, Univ. Tasmania,

McLean, D. S., Vercoe, D., Stack, K. R., and Richardson, D. (2005a). "The colloidal pKa of lipophilic extractives commonly found in Pinus radiata," Appita J. 58(5), 362-366.

McLean, D. S., Stack, K. R., and Richardson, D. E. (2005b). "The effect of wood extractives composition, $\mathrm{pH}$ and temperature on pitch deposition," Appita J. 58(1), 52-56. 
McLean, D. S., Stack, K. R., and Richardson, D. E. (2010). "Evaluation of cationic polymers to control pitch deposition," Appita J. 63(3), 199-205. DOI: 10.1007/978-0387-77845-7_23

Mesmer, R. E., Patterson, C. S., Busey, R. H., and Holmes, H. F. (1989). "Ionization of acetic-acid in $\mathrm{NaCl}(\mathrm{aq})$ media - A potentiometric study to $573-\mathrm{K}$ and 130-bar," $\mathrm{J}$. Phys. Chem. 93(21), 7483-7490. DOI: 10.1021/j100358a044

Meyer, E. E., Rosenberg, K. J., and Israelachvili, J. (2006). "Recent progress in understanding hydrophobic interactions," Proc. Nat. Acad. Sci. USA 103(43), 1573915746. DOI: 10.1073/pnas.0606422103

Negro, C., Blanco, A., Saarimaa, V., and Tijero, J. (2005). "Optimization of pitch removal by dissolved air flotation in a eucalyptus kraft mill," Sep. Sci. Technol. 40(5), 1129-1143. DOI: 10.1081/SS-200048173

Nyrén, V., and Back, E. (1958a). "The ionization constant, solubility product and solubility of lauric and myristic acid," Acta Chem. Scand. 12, 1305-1311. DOI: 10.3891/acta.chem.scand.12-1305

Nyrén, V., and Back, E. (1958b). "Ionization constant, solubility product, and solubility of abietic and dehydroabietic acid," Acta Chem. Scand. 12, 1516-1520. DOI: 10.3891/acta.chem.scand.12-1516

Ocko, B. M., Kelley, M. S., Nikova, A. T., and Schwartz, D. K. (2002). "Structure and phase behavior of mixed monolayers of saturated and unsaturated fatty acids," Langmuir 18(25), 9810-9815. DOI: 10.1021/la026079y

Ödberg, L., Lindström, T., Liedberg, B., and Gustavsson, J. (1987). "Evidence for $\beta$ ketoester formation during the sizing of paper with alkylketene dimers," Tappi J. 70(4), 135-139.

Ohno, K., Isogai, A., and Onabe, F. (2002). "Solid-state C-13-NMR analysis of size components in handsheets prepared by fatty acid soap size-alum systems," J. Wood Sci. 48(3), 197-203. DOI: 10.1007/BF00771367

Örså, F., Holmbom, B., and Thornton, J. (1997). "Dissolution and dispersion of spruce wood components into hot water," Wood Sci. Technol. 31(4), 279-290. DOI: $10.1007 / \mathrm{BF} 00702615$

Panagiotopoulos, A. Z. (2009). "Charge correlation effects on ionization of weak polyelectrolytes,” J. Phys. - Conden. Matt. 21(42), article no. 424113. DOI: 10.1088/0953-8984/21/42/424113

Pashkovskaya, A. A., Vazdar, M., Zimmermann, L., Jovanovic, O., Pohl, P., and Pohl, E. E. (2018). "Mechanism of long-chain free fatty acid protonation at the membranewater interface," Biophys. J. 114(9), 2142-2151. DOI: 10.1016/j.bpj.2018.04.011

Pedimonte, B. J., Moest, T., Luxbacher, T., von Wilmowsky, C., Fey, T., Schlegel, K. A., and Greil, P. (2014). "Morphological zeta-potential variation of nanoporous anodic alumina layers and cell adherence," Acta Biomater. 10(2), 968-974. DOI: 10.1016/j.actbio.2013.09.023

Perger, T. M., and Bešter-Rogač, M. (2007). "Thermodynamics of micelle formation of alkyltrimethylammonium chlorides from high performance electric conductivity measurements," J. Colloid Interface Sci. 313(1), 288-295. DOI: 10.1016/j.jcis.2007.04.043

Polimeno, A., Ros, J. M., and Levine, Y. K. (2001). "Monte Carlo computer simulation of spreading pressure-area isotherms of Langmuir monolayers of fatty-acid molecules," J. Chem. Phys. 115(13), 6185-6191. DOI: 10.1063/1.1395058 
Qin, M., Hanuksela, T., and Holmbon, B. (2004). "Deposition tendency of TMP resin and related model mixtures," J. Pulp Paper Sci. 30(10), 279-283.

Richardson, D. E., and Grubb, M. J. (2013). "Evaluation of mineral filler interaction with wood extractive colloids in pulp and paper mill process waters using flow cytometry," J-FOR Journal Sci. Technol. Forests Prod. Proc. 3(2), 16-21.

Richardson, D., Lee, R., Stack, K., Lewis, T., and Garnier, G. (2012). "Process factors affecting colloid stability and deposit formation in manufacture of newsprint from TMP and recycled fibre," Appita J. 65(4), 323-330.

Roberts, J. C., and Garner, D. N. (1985). "The mechanism of alkylketene dimer sizing of paper, Part 1," Tappi J. 68(4), 118-121.

Saarimaa, V., Vahasalo, L., Sundberg, A., Pranovich, A., Holmbom, B., Svedman, M., and Orsa, F. (2006). "Influence of pectic acids on aggregation and deposition of colloidal pitch," Nordic Pulp Paper Res. J. 21(5), 613-619. DOI: 10.3183/npprj2006-21-05-p613-619

Saeeduddin, Khanzada, A. W. K., and Mufti, A. T. (1996). "Dissociation constant studies of citric acid at different temperatures and in different organic-water solvent systems," J. Chem. Soc. Pakistan 18(2), 81-87.

Sanders, J. V., and Spink, V. A. (1955). "Ionization in fatty acid monolayers on pure water," Nature 175(4458), 644-645. DOI: 10.1038/175644a0

Šarac, B., and Bešter-Rogač, M. (2009). "Temperature and salt-induced micellization of dodecyltrimethylammonium chloride in aqueous solution: A thermodynamic study," J. Colloid Interface Sci. 338(1), 216-221. DOI: 10.1016/j.jcis.2009.06.027

Scalfarotto, R. E. (1985). "Remedies for press picking boost efficiency of ASA synthetic sizing," Pulp Paper 1985, 126-129.

Shimada, K., Dumas, D., and Biermann, C. J. (1997). "Properties of candidate internal sizing agents versus sizing performance," Tappi J. 80(10), 171-174.

Sihvonen, A.-L., Sundberg, K., Sundberg, A., and Holmbom, B. (1998). "Stability and deposition tendency of colloidal wood resin," Nordic Pulp Paper Res. J. 13(1), 64-67. DOI: 10.3183/npprj-1998-13-01-p064-067

Singh, S., Stack, K. R., Lewis, T. W., and Richardson, D. E. (2016). "Optimisation of froth flotation for removal of wood extractives in paper manufacture," Appita J. 69(3), 253-263.

Smith, D. (1999). "ASA components: Their synthesis and relative sizing performance," in: Scientific \& Technical Advances in the Internal \& Surface Sizing of Paper \& Board, Paper 8, Pira International, Letherhead, UK.

Sobhana, S. S. L., Zhang, X., Kesavan, L., Liias, P., and Fardim, P. (2017). "Layered double hydroxide interfaced stearic acid - Cellulose fibres: A new class of superhydrophobic hybrid materials," Colloids Surf. A - Physicohem. Eng. Aspects 522, 416-424. DOI: 10.1016/j.colsurfa.2017.03.025

Song, J. L., and Rojas, O. J. (2013). "Approaching super-hydrophobicity from cellulosic materials: A Review," Nordic Pulp Paper Res. J. 28(2), 216-238. DOI: 10.3183/npprj-2013-28-02-p216-238

Stack, K. R., Tham, Y. Y., Lewis, T. W., and Richardson, D. E. (2015). "The effect of pH disturbances on the colloidal structure and fibre adsorption of Pinus radiata wood extractives," Proceedings of the Appita Fibre Value Chain Conference and Expo 2015, 11-12 November 2015, Melbourne, Australia, pp. 72-78.

Stack, K. R., Ngwenya, E., Richardson, D. E., and Lewis, T. W. (2019a). "Colloidal stability of Pinus radiata wood extractives. Part 2: Competing interactions between 
wood extractives and process variables determined from regression modelling," Appita J. 72(2), 94-110.

Stack, K. R., Yaqoob, N., Ngwenya, E., Richardson, D. E., and Lewis, T. W. (2019b). "Colloidal stability of Pinus radiata wood extractives. Part 1: Effect of extractives composition and process variables," Appita J. 72(1), 15-29.

Stigter, D. (1991). "Shielding effects of small ions in gel-electrophoresis of DNA," Biopolymers 31(2), 169-176. DOI: 10.1002/bip.360310205

Strand, A. (2013). The pH-Dependent Phase Distribution of Wood Pitch Components in Papermaking Processes, Laboratory of Wood and Paper Chemistry, Dept. of Chem. Eng., Åbo Akademi University, PhD Dissertation.

Strand, A., Sundberg, A., Vahasalo, L., and Holmbom, B. (2011a). "Aggregation and destabilisation of colloidal wood pitch by calcium ions in TMP suspensions," Nordic Pulp Paper Res. J. 26(4), 429-437. DOI: 10.3183/npprj-2011-26-04-p429-437

Strand, A., Sundberg, A., Vahasalo, L., and Holmbom, B. (2011b). "Influence of pitch composition and wood substances on the phase distribution of resin and fatty acids at different pH levels," J. Dispersion Sci. Technol. 32(5), 702-709, article no. PII 936690825. DOI: 10.1080/01932691.2010.480853

Strand, A., Zasadowski, D., Norgren, M., Hedenström, E., Willför, S., and Sundberg, A. (2012). "Selective froth flotation of pitch components from spruce TMP process water," Appita J. 65(4), 337-346.

Strazdins, E. (1977). "Mechanistic aspects of rosin sizing," Tappi J. 60(10), 102-105.

Strazdins, E. (1989a). "Theoretical and practical aspects of alum use in papermaking," Nordic Pulp Paper Res. J. 4(2), 128-134. DOI: 10.3183/npprj-1989-04-02-p128-134

Strazdins, E. (1989b). "Paper sizes and sizing," in: Naval Stores: Production - Chemistry - Utilization, D. F. Zinkel and J. Russell (eds.), Pulp Chemicals Assoc., New York.

Ström, G. (2000). "Physico-chemical properties and surfactant behavior," in: Pitch Control, Wood Resin and Deresination, E. L. Back and L. H. Allen (eds.), TAPPI Press, Atlanta, Ch. 5, pp. 139-149.

Ström, G., Stenius, P., Lindström, M., and Ödberg, L. (1990). "Surface chemical aspects of the behavior of soaps in pulp washing," Nordic Pulp Paper Res. J. 5(1), 44-51. DOI: 10.3183/npprj-1990-05-01-p044-051

Suckling, I. D., Hua, H. L., and Uprichard, J. M. (1990). "Factors affecting resin removal from Radiata pine mechanical pulps," Appita J. 43(3), 217-221.

Sue, K., Ouchi, F., Minami, K., and Arai, K. (2004). "Determination of carboxylic acid dissociation constants to 350 degrees $\mathrm{C}$ at $23 \mathrm{MPa}$ by potentiometric $\mathrm{pH}$ measurements," J. Chem. Eng. Data 49(5), 1359-1363. DOI: 10.1021/je049923q

Sundberg, A., Ekman, R., Holmbom, B., and Grönfors, H. (1994a). "Interactions of cationic polymers with components in thermomechanical pulp suspensions," Pap. Рии 76(9), 593-598.

Sundberg, A., Strand, A., Vahasalo, L., and Holmbom, B. (2009). "Phase distribution of resin and fatty acids in colloidal wood pitch emulsions at different $\mathrm{pH}$-levels," $J$. Dispersion Sci. Technol. 30(6), 912-919, article number: PII 911746163. DOI: 10.1080/01932690802646249

Sundberg, K., Thornton, J., Ekman, R., and Holmbom, B. (1994b). "Interactions between simple electrolytes and dissolved and colloidal substances in mechanical pulp," Nordic Pulp Paper Res. J. 9(2), 125-128. DOI: 10.3183/npprj-1994-09-02-p125-128 
Sundberg, K., Thornton, J., Pettersson, C., Holmbom, B., and Ekman, R. (1994c). "Calcium-induced aggregation of dissolved and colloidal substances in mechanical pulp suspensions," J. Pulp Pap. Sci. 20(11), J317-J322.

Swanson, J. W., and Cordingley, R. H. (1956). "Surface chemical studies on pitch. I. A new approach to the pitch problem in papermaking," Tappi J. 39(10), 684-690.

Tanase-Opedal, M., Stenius, P., and Johansson, L. (2011a). "Review: Colloidal stability and removal of extractives from process water in thermomechanical pulping," Nordic Pulp Paper Res. J. 26(3), 248-257. DOI: 10.3183/npprj-2011-26-03-p248-257

Tanase-Opedal, M., Stenius, P., Johansson, L., Hill, J., and Sandberg, C. (2011b). "Removal of dissolved and colloidal substances in water from compressive pretreatment of chips using dissolved air flotation, pilot trial," Nordic Pulp Paper Res. J. 26(4), 364-371. DOI: 10.3183/npprj-2011-26-04-p364-371

Tanford, C. (1980). The Hydrophobic Effect: Formation of Micelles and Biological Membranes, $2^{\text {nd }}$ Ed., Wiley, New York, pp. 233.

Tao, Y.-T. (1993). "Structural comparison of self-assembled monolayers of $n$-alkanoic acids on the surfaces of silver, copper, and aluminum," J. Amer. Chem. Soc. 115(10), 4350-4358. DOI: $10.1021 /$ ja00063a062

Tayeb, A. H., Hubbe, M. A., Tayeb, P., Pal, L., and Rojas, O. J. (2017a). "Soy proteins as a sustainable solution to strengthen recycled paper and reduce deposition of hydrophobic contaminants in papermaking: A bench and pilot-plant study," ACS Sustain. Chem. Eng. 5(8), 7211-7219. DOI: 10.1021/acssuschemeng.7b01425

Tayeb, A. H., Hubbe, M. A., Zhang, Y. X., and Rojas, O. J. (2017b). 'Effect of lipoxygenase oxidation on surface deposition of unsaturated fatty acids," Langmuir 33(18), 4559-4566. DOI: 10.1021/acs.langmuir.7b00908

Tayeb, A. H., Sadeghifar, H., Hubbe, M. A., and Rojas, O. J. (2017c). "Lipoxygenasemediated peroxidation of model plant extractives," Indust. Crops Prod. 104, 253-262. DOI: $10.1016 /$ j.indcrop.2017.04.041

Theander, K., and Pugh, R. J. (2004). "Surface chemicals concepts of flotation deinking," Colloids Surf. A - Physicochem. Eng. Aspects 240, 111-130. DOI: 10.1016/j.colsurfa.2003.12.014

Torrent-Burgués, J. (2018). "Thermodynamic behaviour of mixed films of an unsaturated and a saturated polar lipid (oleic acid-stearic acid and POPC-DPPC)," Colloids Interfaces 2(2), article no. UNSP 17. DOI: 10.3390/colloids2020017

Touwslager, F. J., and Sondag, A. H. M. (1994). "Order and disorder in $n$-alkylcarboxylic acid monolayers. Chain-length dependence and lateral interaction effects," Langmuir 10(4), 1028-1033. DOI: 10.1021/la00016a013

Vaknin, D., Bu, W., Satija, S. K., and Travesset, A. (2007). “Ordering by collapse: Formation of bilayer and trilayer crystals by folding Langmuir monolayers," Langmuir 23(4), 1888-1897. DOI: 10.1021/la062672u

Valto, P., Knuutinen, J., and Alen, R. (2012). "Overview of analytical procedures for fatty and resin acids in the papermaking process," BioResources 7(4), 6041-6076. DOI: 10.15376/biores.7.4.6041-6076

Vandenberg, E. J., and Spurlin, H. M. (1967). "Mechanism of rosin sizing of paper," Tappi J. 50(5), 209-224.

Vercoe, D., Stack, K., Blackman, A., Yates, B., and Richardson, D. (2004). "An innovative approach characterising the interactions leading to pitch deposition," $J$. Wood Chem. Technol. 24(2), 115-137. DOI: 10.1081/WCT-200026562 
Vollhardt, D. (2007). "Effect of unsaturation in fatty acids on the main characteristics of Langmuir monolayers," J. Phys. Chem. C 111(18), 6805-6812. DOI: 10.1021/jp0704822

Vollhardt, D., and Fainerman, V. B. (2006). "Progress in characterization of Langmuir monolayers by consideration of compressibility," Adv. Colloid Interface Sci. 127(2), 83-97. DOI: 10.1016/j.cis.2006.11.006

Wang, Z. N., Wu, T. H., Zhou, W., Wei, X. L., and Zhao, J. (2011). "Surface properties and micellar molecular interaction in binary systems of a biosurfactant sodium deoxycholate (NaDC) with conventional surfactants," J. Surfactants Detergents 14(3), 391-400. DOI: 10.1007/s11743-010-1242-3

Wellen, B. A., Lach, E. A., and Allen, H. C. (2017). "Surface $\mathrm{p} K_{\mathrm{a}}$ of octanoic, nonanoic, and decanoic fatty acids at the air-water interface: Applications to atmospheric aerosol chemistry," Phys. Chem. Chem. Phys. 19(39), 26551-26558. DOI: 10.1039/c7cp04527a

Wen, X., and Franses, E. I. (2000). "Effect of protonation on the solution and phase behavior of aqueous sodium myristate," J. Colloid Interface Sci. 231(1), 42-51. DOI: 10.1006/jcis.2000.7156

White, J. R. (1950). "Dissociation constants of higher alkyl phosphate esters, phosphonic acids, phosphonous acids, phosphinic acids and carboxylic acids," J. Am. Chem. Soc.72(4), 1859-1860. DOI: 10.1021/ja01160a530

Yodkhum, K., and Phaechamud, T. (2014). "Hydrophobic chitosan sponges modified by aluminum monostearate and dehydrothermal treatment as sustained drug delivery system," Mater. Sci. Eng. C-Mater. Biol. Appl. 42, 715-725. DOI: 10.1016/j.msec.2014.06.019

Zana, R. (1996). "Critical micellization concentration of surfactants in aqueous solution and free energy of micellization," Langmuir 12(5), 1208-1211. DOI: $10.1021 / 1 \mathrm{la950691q}$

Zana, R. (1997). "Micellization of amphiphiles: Selected aspects," Colloids Surf. A Physicochem. Eng. Aspects 123-124, 27-35. DOI: 10.1016/S0927-7757(96)03788-0

Zasadowski, D., Strand, A., Sundberg, A., Edlund, H., and Norgren, M. (2013). "Selective purification of bleached spruce TMP process water by induced air flotation (IAF)," Holzforschung 68(2), 157-165. DOI: 10.1515/hf-2013-0045

Zhang, J. H., Kleinöder, T., and Gasteiger, J. (2006). "Prediction of $\mathrm{p} K_{\mathrm{a}}$ values for aliphatic carboxylic acids and alcohols with empirical atomic charge descriptors," $J$. Chem. Inform. Modeling 46(6), 2256-2266. DOI: 10.1021/ci060129d

Zhang, X., Nguyen, D., Paice, M. G., Tsang, A., and Renaud, S. (2007). Degradation of wood extractives in thermo-mechanical pulp by soybean lipoxygenase. Enzyme Microbial Technology, 40(4), 866-873. DOI: 10.1016/j.enzmictec.2006.06.021

Zhang, X., Renaud, S., and Paice, M. (2005). The potential of laccase to remove extractives present in pulp and white water from TMP newsprint mills. J. Pulp Paper Sci., 31(4), 175-180. 